\title{
Response Properties of Nociceptive and Low-Threshold Mechanoreceptive Neurons in the Hamster Superior Colliculus
}

\author{
Michelle A. Larson, ${ }^{a}$ John G. McHaffie, and Barry E. Stein \\ Department of Physiology, Medical College of Virginia, Richmond, Virginia 23298
}

There are many somatosensory neurons in the hamster superior colliculus (SC); some respond to innocuous tactile stimuli, while others respond either preferentially, or solely, to noxious stimuli. Yet, there are little quantitative data describing the responses of these neurons. We sought to provide such information by relating stimulus intensity to the magnitude of the neural response using controlled innocuous and noxious mechanical and thermal stimuli.

Of 122 somatosensory SC neurons studied in urethaneanesthetized hamsters, the majority $(52 \%)$ had low-threshold mechanoreceptive properties (LT). LT neurons had force thresholds less than $1 \mathrm{gm}$, adapted rapidly to maintained stimuli, and did not respond with higher numbers of impulses to noxious mechanical or thermal stimuli. A smaller, though substantial, proportion of neurons $(45 \%)$ responded either preferentially, or solely, to noxious stimuli. A few neurons $(3 \%)$ were inhibited by either light tactile or noxious mechanical stimuli. Two populations of nociceptive neurons were found and classified either as (1) wide dynamic range (WDR) neurons $(n=25)$, those that responded to gentle mechanical, noxious mechanical, and/or thermal stimuli; or (2) nociceptive-specific (NS) neurons $(n=30)$, those that responded solely to high-intensity mechanical or noxious thermal stimuli. WDR neurons responded monotonically to increases in the intensity of innocuous mechanical stimuli, and displacement-response relationship for this population was a slightly negatively accelerating power function with an exponent of $\mathbf{0 . 7 8 5}$. However, the thermal stimulus-response relationships (to graded skin temperatures) of both WDR and NS neurons were positively accelerating power functions with exponents of 2.3 and $2.5\left(r^{2}=0.988\right)$, respectively. These values are consistent with both electrophysiological data from dorsal horn nociceptive neurons and from human psychophysical results using the same range of thermal stimuli.

These experiments demonstrate that SC neurons are ca-

\footnotetext{
Received Mar. 18, 1986; revised Aug. 7, 1986; accepted Aug. 11, 1986.

We wish to thank Dr. Donald Price for his helpful suggestions in the analysis of the data; Dr. Vernon Chinchilli for his statistical assistance; Dr. Alex Clarke and colleagues of the Biomedical Instrumentation Facility for their construction of the tactile and thermal stimulation devices; and Mrs. Isabel Sluder for secretarial assistance.

This work was supported by NIH Grant EY05554 and a grant from the Jeffress Foundation.

Correspondence should be addressed to Dr. Barry E. Stein, Department of Physiology, Box 551, Medical College of Virginia, Richmond, VA 23298-0001.

a Present address: University of Southern California, Department of Physical Therapy, 12933 Erickson Avenue, Downey, CA 90242.
}

Copyright (C) 1987 Society for Neuroscience $0270-6474 / 87 / 020547-18 \$ 02.00 / 0$ pable of signaling not only the presence and location of a noxious stimulus but its intensity as well. Presumably, these neurons play a significant role in the animal's reactions to potentially harmful stimuli. The partial laminar segregation of WDR and NS neurons may reflect different involvements of particular nociceptive subtypes in the various overt responses mediated by the SC.

The superior colliculus (SC) is known to be involved in attentive and orientation behavior initiated by a variety of innocuous sensory stimuli (Sprague and Meikle, 1965; Schneider, 1969), and most current discussions of the $\mathrm{SC}$ center about these functions. Such behaviors refiect primarily the activity of deep laminae neurons (Casagrande et al., 1972), for it is the deep laminae neurons that maintain widspread connections with premotor and motor areas of the brain stem and spinal cord through which SC-mediated orientation responscs arc cffected (see Huerta and Harting, 1984, for a recent review). Neurons of the deep laminae are responsive to visual, auditory, and somatosensory stimuli (Stein and Arigbede, 1972; Gordon, 1973; Chalupa and Rhoades, 1977; Allon and Wollberg, 1978; Nagata and Kruger, 1979; Stein and Dixon, 1979), with each sensory representation being topographic and in approximate register with the others (Drager and Hubel, 1975; Stein et al., 1976; Tiau and Blakemore, 1976; Chalupa and Rhoades, 1977; Finlay et al., 1978; Gaither and Stein, 1979; Stein and Dixon, 1979). Electrical stimulation of the deep laminae evokes coordinated contralateral orientation of the eyes, pinnae, and head (e.g., Schaefer, 1970; Robinson, 1972; Stein et al., 1976; Stein and Clamann, 1981; McHaffie and Stein, 1982), so that the various receptor organs are directed toward the same area of space represented at the stimulation site. This topographical register among sensory and motor maps appears to be the simplest way to transform different sensory cues into appropriate motor behaviors (see Stein, 1984).

Some early investigators, however, believed that the SC played a significant role in pain (Walker, 1943; Crosby and Henderson, 1948; Reyes et al., 1951; Spiegel et al., 1954; Delgado, 1965). This belief was based on 2 observations: (1) high-intensity electrical stimulation of the SC produces pain in man as well as behavior indicative of pain in cat (Reyes et al., 1951; Spiegel et al., 1954; Delgado, 1965; Nashold et al., 1969), and (2) the SC receives an input from the anterolateral funiculus, a pathway known to contain the axons of nociceptive neurons (Walker, 1942, 1943; Mehler, 1969). More recent anatomical studies also have provided evidence consistent with the possible tectopetal target of nociceptors via a variety of routes: the trigeminal system (Killackey and Erzurumlu, 1981; Rhoades, 1981a; Bruce et al., 1984; McHaffie et al., 1984), and the lateral cervical 
nucleus (Antonetty and Webster, 1975; Rhoades, 1981a), as well as some direct projections originating from laminae of the spinal cord in which nociceptive neurons are located (Stewart and King, 1963; Antonetty and Webster, 1975; Rhoades, 1981a).

Certainly, the existence of an input that will signal potentially harmful stimuli to a structure involved in attentive and orientation responses makes adaptive sense. Until recently, however, the data were far from conclusive. Electrical stimulation of the SC with the intensities used in early studies might have elicited responses linked to pain because of current spread to areas such as the periaqueductal gray and subjacent tegmentum, regions long known to be involved in pain. Furthermore, each of the sources of afferent information contains mixtures of neuron types, only a fraction which are involved with nociception. The equivocal nature of these results, as well as a growing body of detailed information relating the role of the $\mathrm{SC}$ in organizing responses to innocuous stimuli, steered investigators toward questions unrelated to possible involvements of the SC in nociception.

It was not until 1978 that the first direct physiological evidence was provided showing that the SC contains neurons that respond preferentially, and others that respond solely, to noxious stimuli (Stein and Dixon, 1978). The responses of these neurons to noxious stimuli could be selectively inhibited by narcotics and, thus, react in much the same way as neurons in more traditionally nociceptive-related structures. The presence of SC neurons responsive to noxious stimuli was later confirmed and extended by Rhoades et al. (1983), who showed that innocuous and noxious stimuli could interact with each other in the same SC neuron. While physiological studies demonstrated unequivocally the presence of nociceptive-like neurons in the $\mathrm{SC}$, they were qualitative in nature and did not indicate whether these neurons could actually encode the specific features of the noxious stimulus, as do nociceptive neurons elsewhere in the nervous system.

The present experiments were initiated, therefore, to examine these questions by evaluating the receptive field features of nociceptive SC neurons and quantitatively relating the intensity of mechanical and thermal stimuli within the innocuous and noxious ranges to their responses. These experiments revealed an unexpected variety of physiologically distinct nociceptive neuronal types in the SC whose properties are remarkably similar to those of dorsal horn neurons. The range of neuronal types and encoding capabilities of nociceptive SC neurons may make it possible for the $\mathrm{SC}$ to play roles in both motivational-affective and sensory-discriminative aspects of pain. Preliminary reports describing some of these data have been presented previously (Larson and Stein, 1984, 1985).

\section{Materials and Methods}

Surgical preparation. Twenty-six adult golden hamsters (Mesocricetus auratus) weighing $80-160 \mathrm{gm}$ were used in the present experiments. All animals were anesthetized with urethane $(1.3 \mathrm{gm} / \mathrm{kg}$, i.p.) mixed with prednisolone (Depo-medrol, $8 \mathrm{mg} / \mathrm{kg}$ ) to minimize cerebral edema, and atropine sulfate was administered $(0.4 \mathrm{mg} / \mathrm{kg}, \mathrm{i} . \mathrm{m}$.) to reduce fluid secretions. Anesthesia was maintained during the experiment with supplemental doses $(0.25 \mathrm{gm} / \mathrm{kg})$ of urethane as required. In order to present thermal stimuli directly on the skin, each animal was shaved, and a depilatory was applied to remove all body hair contralateral to the recording site. The skin was then painted black, and a flat movable Plexiglas plate was positioned against the pinna to facilitate mapping receptive fields there. The animal's body temperature was monitored with a rectal probe and maintained at $37^{\circ} \mathrm{C}$ by covering the animal with a plastic blanket and keeping it on a circulating hot water pad.
Each hamster was placed in a modified stereotaxic headholder by means of a horizontal bar attached to the skull with self-tapping screws and dental acrylic. The bar was positioned to allow an unobstructed visual field as well as access to all parts of the body for the delivery of tactile stimuli. A cranial opening was made with a high-speed drill to expose the left visual cortex, and the dura was reflected. The exposed brain was kept at $35-37^{\circ} \mathrm{C}$ throughout the experiment by bathing it with warmed mineral oil.

Recording procedures. Flectrode penetrations were made vertically through the brain with glass-insulated tungsten microelectrodes (Levick, 1972), tip exposure, $8-18 \mu \mathrm{m}$. The electrode was lowered to the surface of the SC with a manual micromanipulator and then advanced through its deeper laminae (below stratum opticum) with a hydraulic microdrive. The locations of neurons were recorded in microns along each electrode track and later confirmed histologically. Standard single-unit extracellular recording techniques were employed, and unit discharges were amplified, displayed on an oscilloscope, and presented over an audiomonitor.

Stimulation procedures. Somatosensory SC neurons were sought by continuously stimulating the skin with brushes and flattened or toothed forceps as the electrode was advanced. Once a neuron was isolated, its receptive field was mapped with the adequate stimulus. Only well-isolated neurons with a signal-to-noise ratio greater than 2:1 were studied. The neurons studied here usually could be recorded over a distance exceeding $100 \mu \mathrm{m}$ and had wave shapes indicative of somal and/or dendritic recording (Hubel, 1960; Bishop et al., 1962). Thus, it is assumed that all the data presented here were derived from SC neurons.

Responses and thresholds to mechanical stimulation were evaluated using camel's hair brushes, calibrated von Frey filaments ( $5 \mathrm{mg}-75 \mathrm{~g}$ ), and manual innocuous and noxious compression of the skin. Flattened and toothed forceps were used to produce moderately intense and frankly noxious mechanical stimulation, respectively. These stimuli were used to delineate the borders of each receptive field as well as the sensitivity gradients within the receptive field. After mapping the receptive field, the latency to electrical stimulation (rectangular cathodal pulses, $2 \mathrm{msec}$ duration, $0.1-3 \mathrm{~mA}$ ) within the receptive field was determined with a pair of fine percutaneous needle electrodes $(1 \mathrm{~mm}$ separation). All latencies were measured from positions within a limited area of the body (i.e., face and proximal trunk) to allow direct comparisons among neurons with different response properties.

Controlled mechanical stimulation (skin displacement) was performed with an electronically controlled moving-coil vibrator (Ling, model $102 \mathrm{~A}$ ) that was activated by ramp, trapezoidal, and triangular pulses. A probe with a flattened or rounded tip ( $1 \mathrm{~mm}$ diameter) was attached to the vibrator with its tip oriented perpendicular to the skin. The stimulus parameters (e.g., velocity, amplitude, duration, and iterative rate) used to study somatosensory neurons could be varied precisely. For most neurons, the duration of each stimulus was $1.5 \mathrm{sec}$. The effectiveness of a mechanical stimulus was evaluated by counting the number of impulses elicited in a $500 \mathrm{msec}$ period beginning at the onset of skin indentation, and once again at its release. In evaluating the effects of varying any given stimulus parameter (e.g., amplitude of displacement), 16 identical stimulus repetitions at an interstimulus interval of $5 \mathrm{sec}$ were used for each stimulus level presented.

Responses to thermal stimulation were first evaluated using an ember. The ember was held 2-4 $\mathrm{mm}$ from the surface of the skin only long enough to produce a noxious response without apparent tissue damage. The stimulus was used to outline the area of the receptive field sensitive to thermal stimulation. Quantitative measurement of responses to rapid temperature shifts was performed 5-15 min later using an electronically controlled programmable contact thermode originally designed at the Neurobiology and Anesthesiology Branch, National Institute of Dental Research and modified by the Biomedical Instrumentation Facility, Medical College of Virginia. The thermode consists of a copper plate electrically heated by a nichrome coil and controlled by a thermistor to regulate heater voltage. The unit is cooled via a water-circulating mechanism, which provides a rapid return to the adapting, or baseline, temperature. Thus, the intensity and duration of the thermal stimuli could be precisely controlled. The thermode was placed over the receptive field and contacted an 8-mm-diameter circular area of skin. An electronic gate allowed the experimenter to switch among any selected skin temperatures. A baseline skin temperature of $35^{\circ} \mathrm{C}$ could be preset, as could each desired temperature above this level. Initially, a thermistor was placed percutaneously to determine the actual skin temperature and to compare this value to that indicated on the thermode itself. A 0.7- 
$1.2^{\circ} \mathrm{C}$ difference between the thermode temperature and actual skin temperature was found; this was corrected for in the measures provided, so that all temperatures in Results represent skin temperatures. Unlike the tests of mechanoreceptive properties, each specific thermal stimulus temperature was presented only once in a given series of trials (when possible the entire series was repeated in ascending and descending order) to minimize sensitization, which has been reported to lead to enhanced responsiveness and spuriously high response rates in subsequent tests (Bessou and Perl, 1969; Fitzgerald and Lynn, 1977). The preprogrammed format consisted of a $5 \mathrm{sec}$ pulse that changed the skin temperature (rate of rise $=9^{\circ} \mathrm{C} / \mathrm{sec}$ ) from baseline $\left(35^{\circ} \mathrm{C}\right.$ ) to $42^{\circ} \mathrm{C}$; readaptation to bascline for $3 \mathrm{~min}$ or more; and progessively higher temperature shifts on subsequent trials to $44,46,48$, and $50^{\circ} \mathrm{C}$. Impulses were counted for a $1 \mathrm{sec}$ period $1 \mathrm{sec}$ prior to the thermal presentation, throughout the $5 \mathrm{sec}$ duration of the thermal stimulus, and for a $1 \mathrm{sec}$ period $1 \mathrm{sec}$ after stimulus termination. Impulses were counted by coupling the amplified discharges to a Schmitt trigger and connecting the trigger to an Ortec 770 counter. Peristimulus time histograms and rasters of unit activity were constructed using an Ortec histogram analyzer and a W.P.I. raster-stepper.

Histological procedures. For all successful electrode penetrations, small electrolytic lesions were made by passing 12-15 $\mu \mathrm{A}$ cathodal current through the electrode tip for $20 \mathrm{sec}$. After terminating a recording session, the animal was deeply anesthetized with sodium pentobarbital and perfused through the heart with saline followed by $10 \%$ formalin. The brain was removed and blocked stereotaxically. Frozen sections were cut at $50 \mu \mathrm{m}$ and stained with cresyl violet for histological reconstruction of electrode tracks and laminar localization of all recorded units.

Data analysis. For analysis of the data generated by innocuous mechanical displacement of the skin, the following equation was used: In (number of impulses) $=\alpha+\beta \ln$ (displacement, in $\mathrm{mm}+1$ ), where $\alpha$ is the $Y$-intercept and $\beta$ the slope. This model (and the statistics described below) described the variations in neuronal responses with $>99 \%\left(r^{2}=\right.$ 0.994 ) accuracy. For analysis of thermal (noxious) stimuli, the same equation was used except the adapting temperature was taken into account: $\ln$ (number of impulses) $=\alpha+\beta \ln$ (temperature $-35^{\circ} \mathrm{C}$ ). This model (using the statistics shown below) described the variations in neuronal responses with $>98 \%\left(r^{2}=0.988\right)$ accuracy. The data from wide dynamic range (WDR) and nociceptive-specific (NS) neurons were analyzed separately.

The data from each population -i.e., low threshold (LT), WDR, NSwere analyzed using a repeated-measures analysis of covariance (Steel and Torrie, 1980) that provided the basis for curve-fitting. The power of this test is in its ability to take into account the variabilty among cells in the sample population. Rather than averaging the responses at each stimulus intensity and calculating a linear regression of these points, the analysis of covariance method allows each neuron within a population (e.g., WDR or NS) to have its own $Y$-intercept, and each point in the response profile of each neuron is used in the analyses which generates a slope reflective of the group. Comparisons among populations were conducted using an $F$ test.

\section{Results}

The dorsal surface of the $\mathrm{SC}$ was identified by the presence of many visually responsive neurons. As the microelectrode was advanced, single- and multiple-unit activity evoked by brushing, tapping, or squeezing the skin was encountered beginning at a depth corresponding to the intermediate laminae and continuing throughout the deepest aspects of the structure. No somatosensory neurons were found in superficial laminae, and, thus, all neurons studied in these experiments were confined to the intermediate and deep laminae.

Once a somatosensory neuron was well isolated, its receptive field was mapped and the response properties characterized. Since the animal was shaved, the effects of hair movement could not be distinguished from stimulation of the skin. Of the 122 somatosensory SC neurons studied, the majority $(63 / 122=52 \%)$ responded optimally to gentle stroking of the skin with a camel's hair brush. Most $(55 / 122=45 \%)$ of the remaining neurons were activated either preferentially, or exclusively, by noxious stim-
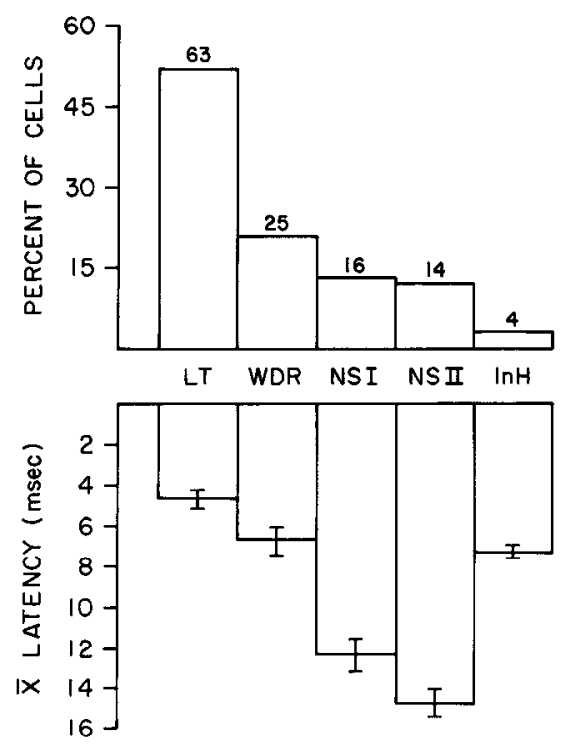

Figure 1. Percentage of different populations of somatosensory SC neurons and their corresponding minimum mean latencies. Latencies were calculated on the basis of electrical stimulation using the stimulus intensity evoking the shortest response latency (first impulse). The mean latency obtained from face and forelimb was $4.8 \mathrm{msec}$ for low-threshold (LT) neurons, $6.8 \mathrm{msec}$ for wide dynamic range (WDR) neurons, 12.8 msec for nociceptive-specific (NSI) neurons, $15.1 \mathrm{msec}$ for nociceptivespecific II (NSII) neurons, and $7.2 \mathrm{msec}$ for inhibitory (InH) neurons. Note that the SC neurons having the highest mechanical thresholds (NSI and NSII) also had the longest mean latencies. The number above each bar represents the number of cells in that group, and the vertical line through each bar represents the SEM.

ulation; a few $(4 / 122=3 \%)$ exhibited an inhibition of ongoing spontaneous activity when either a light tactile or a noxious pinch was applied. Although the primary objective of the present study was to characterize the response properties of nociceptive neurons, many $(30 / 63=48 \%)$ LT neurons encountered were studied in detail using controlled mechanical stimulation. This was done to distinguish their properties from neurons that were capable of responding to both innocuous and noxious stimuli. The properties of these LT neurons are described below.

\section{Neurons responding to innocuous stimulation: low} threshold

Neurons responding maximally to light touch or stroking of the skin with a camel's hair brush were encountered in all regions of the intermediate and deep laminae of the SC. The responses elicited by these stimuli were transient; continuous responses could be evoked only by continually brushing or tapping the skin. Force thresholds were determined by von Frey filaments, and threshold was considered to be that bending force that reliably elicited a response. Thresholds were always less than 1 $\mathrm{gm}$, and in most cases $(70 \%)$ less than $100 \mathrm{mg}$. These neurons required low-intensity electrical stimulation $(0.1-0.7 \mathrm{~mA})$ for activation and had short latencies $(4.0-5.2 \mathrm{msec}$ ) (Fig. 1). Noxious mechanical stimulation within the receptive field did not elicit greater numbers of impulses than did innocuous mechanical stimuli, and none of these neurons responded to changes in skin temperature in the ranges employed $\left(42-50^{\circ} \mathrm{C}\right)$. Afferents activated by low-intensity mechanical stimuli are classified as LT mechanoreceptive (Burgess and Perl, 1973) and share many of the same qualitative characteristics as those observed in the present study. This same classification is used here. 


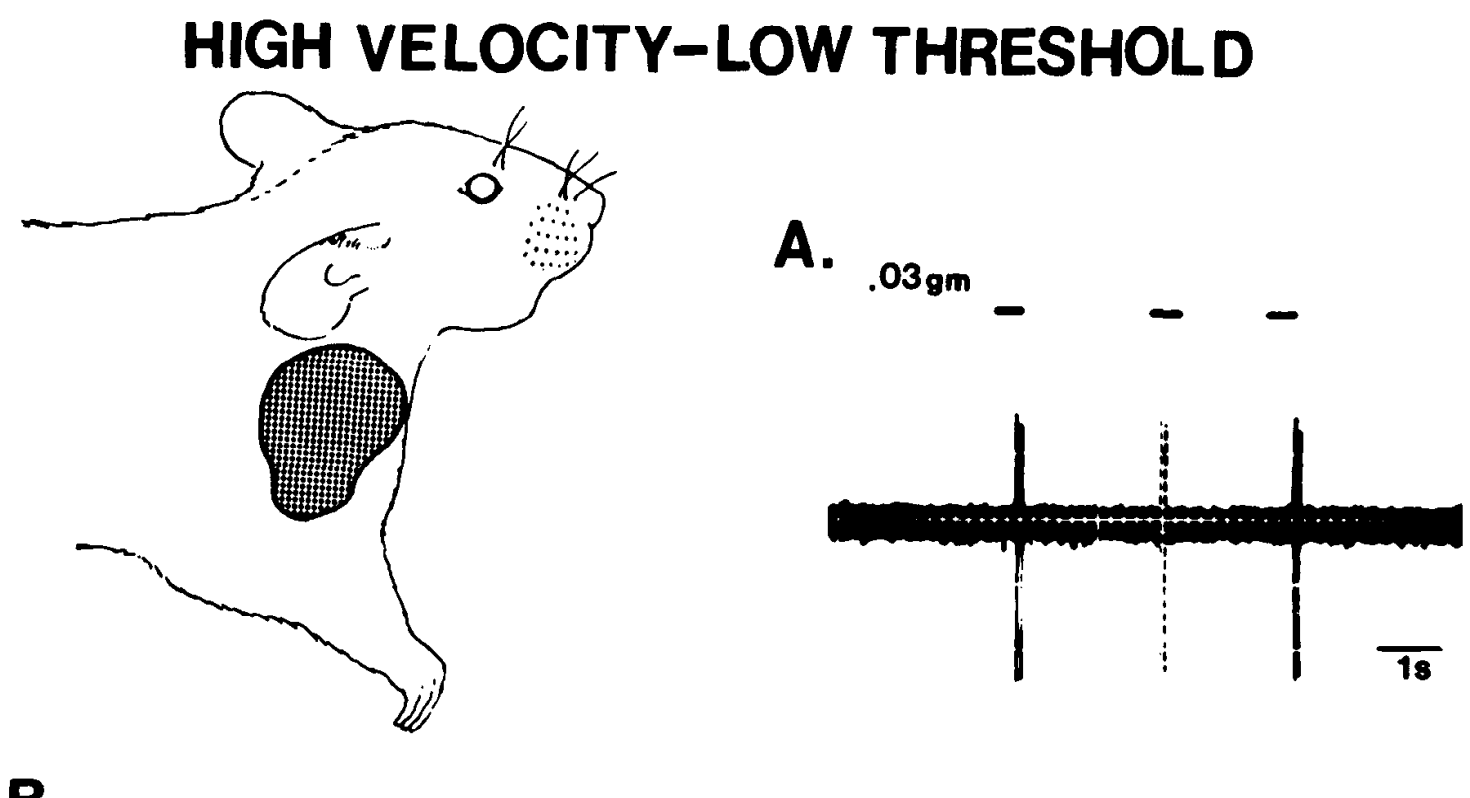

B.
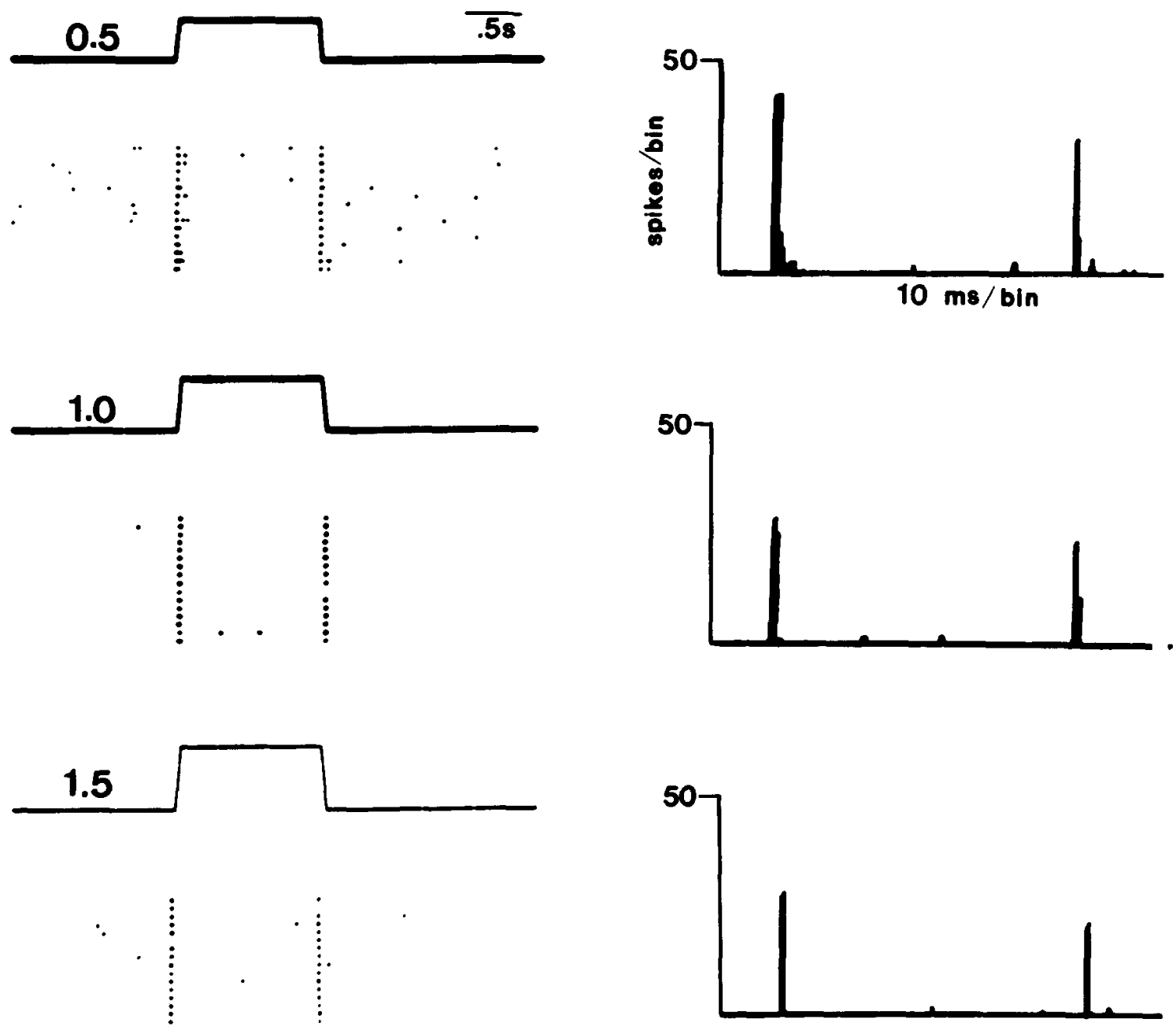

Figure 2. Responses of a high-velocity, low-threshold (LT) neuron in stratum griseum intermediale to controlled mechanical skin displacement. The receptive field was located on the proximal forelimb, as indicated by stippled area on the animal outline. $A$, Threshold responses elicited by stimulation with a $30 \mathrm{mg}$ von Frey filament (horizontal lines). B. Controlled mechanical skin displacement $(350 \mu \mathrm{m} / \mathrm{msec})$ at amplitudes of 0.5 , 1.0 , and $1.5 \mathrm{~mm}$ (at left of each stimulus trace) evoked 1-3 impulses at the onset and offset of the stimulus. This is illustrated in the left-right pairs of rasters and peristimulus time histograms (right) composed of 16 successive trials at each amplitude of displacement. Rasters are ordered from 
The receptive fields of LT neurons were contralateral to the recording site and ranged in size from $3 \mathrm{~mm}^{2}$ to the entire contralateral body. Neurons with small receptive fields $\left(<1 \mathrm{~cm}^{2}\right)$ on the face and forelimb had well-defined borders and were encountered in the rostral SC. Neurons with larger receptive fields located on the trunk and hindlimb were found in the caudal aspect of the SC, and thus the previously described somatotopic organization of the rodent SC (Tiao and Blakcmorc, 1976; Chalupa and Rhoades, 1977; Finlay et al., 1978; Stein and Dixon, 1979) was confirmed here.

Many $(14 / 30=46 \%)$ of the LT neurons responded to small $(0.1 \mathrm{~mm})$ controlled mechanical displacement of the skin, and all responded to displacement of $0.5 \mathrm{~mm}$ or less. To evaluate the velocity requirements of these neurons, a series of progressively higher stimulus velocities was presented at the optimal amplitude of displacement. Rapid skin displacement was necessary to activate the majority of neurons $(23 / 30=77 \%)$, and a brief response of 1-3 impulses was evoked at On (indentation) and Off (release). No consistent differences in the number of impulses elicited at $O n$ and Off were apparent in these neurons. Several $(7 / 20=23 \%)$ were activated by low velocities, and, unlike high-velocity SC neurons, a train of impulses was evoked reliably.

Response properties similar to those described above are exhibited by rapidly adapting cutaneous primary afferent fibers from hairy skin in primates (Iggo, 1963; Perl, 1968; Merzenich and Harrington, 1969) and other mammals (Burgess et al., 1968; Bromberg and Whitehorn, 1974; Iggo and Andres, 1982), in that responses are evoked only during the dynamic phase of skin stimulation. As a group, both primary afferent neurons and $\mathrm{SC}$ neurons demonstrate a continuum of velocity requirements for activation. In the present experiments, high-velocity LT SC neurons adapted rapidly to maintained skin displacements and did not continue to discharge during static displacement even when maximum amplitude of displacement $(3 \mathrm{~mm})$ was used. However, a brief after-discharge was observed with high amplitudes of skin displacement by those neurons also activated by low velocities; this same feature has been described for firstorder afferents (Brown and Iggo, 1967). However, none of the LT neurons in the SC demonstrated the response characteristics of slowly adapting first-order mechanoreceptors commonly found in hairy and glabrous skin (Burgess and Perl, 1973; Iggo, 1977).

A typical example of a LT neuron requiring high-velocity skin displacement is illustrated in Figure 2. This intermediate lamina neuron responded best when a camel's hair brush was moved rapidly across the skin and had a force threshold of $30 \mathrm{mg}$. Pinching the skin with flattened or toothed forceps did not produce an appreciable increase in the number of impulses above that elicited with innocuous mechanical stimuli. In order to determine the relationship between stimulus velocity and neuronal responses, the electromechanical stimulator was used to present an ascending series of velocities at a constant amplitude of skin displacement. A very high velocity $(350 \mathrm{~mm} / \mathrm{sec})$ was required for reliable activation of this neuron, and at this velocity, a $0.5 \mathrm{~mm}$ skin identation evoked a burst of 1-3 impulses at both $\mathrm{On}$ and Off. This was the maximum response that could be elicited from this neuron, and increasing the amplitude of skin indentation did not alter it. A similar response pattern was evident in each of the high-velocity SC neurons studied.

The distinctive properties of a second, smaller population of SC neurons responsive to low-velocity stimulation are illustrated in Figure 3. This neuron was activated by slowly brushing across the skin and by gradual skin displacements. These stimuli cvoked a train of impulses rather than the brief burst of impulses typical of high-velocity neurons. During the dynamic phase of skin displacement, the neuron continued to discharge but ceased to respond during static displacement. At high stimulus amplitudes, an after-discharge was evoked and extended into the initial portion of the static phase of the stimulus. This was typical of the population of low-velocity SC neurons studied. The population of LT neurons (both high and low velocity) appeared to have many of the properties associated with first-order afferents that respond only while displacement is changing. Thus, the classification of velocity detectors (Brown and Iggo, 1967; Burgess and Perl, 1973) seems well suited to these SC neurons.

Neurons responding maximally to noxious stimulation: WDR and nociceptive-specific neurons

Neurons responding either preferentially or exclusively to noxious mechanical stimulation were frequent and widely distributed throughout the intermediate and deep laminae of the SC. They were intermingled with a variety of different types of somatosensory neurons and exhibited a somatotopic pattern similar to that of LT neurons. The receptive fields of neurons responding to noxious stimuli were classified according to their responses to controlled innocuous and noxious mechanical and thermal stimulation.

\section{WDR neurons}

Twenty-five (20\%) SC neurons were found to respond to lowintensity mechanical stimuli like those that evoked optimal responses in the LT neurons described earlier. Like LT neurons, these neurons responded to very light touch, tapping, or brushing of the skin and had force thresholds always less than $1 \mathrm{gm}$. Furthermore, these neurons had response latencies to electrical stimulation only slightly longer than those of the LT neurons described above (4.0-7.2 vs $2.5-5.2 \mathrm{msec}$; see Fig. 1). Unlike LT neurons, however, these neurons responded with progressively more impulses to more intense compression of the skin and exhibited their highest discharge rates to noxious compression with a toothed forceps. Moreover, the responses evoked by intense cutaneous compression were sustained during maintained stimulation and outlasted (for up to several minutes) the duration of the stimulus. These neurons also responded to heating the skin, and an ember held 2-4 $\mathrm{mm}$ away from the receptive field always evoked a vigorous and maintained response. The discharges elicited by both noxious pinch and noxious thermal stimulus were characterized by a gradual acceleration to a peak discharge rate, followed by an adaptation to a new sustained level of activity.

The receptive fields of these neurons were large $\left(7-9 \mathrm{~cm}^{2}\right)$ and usually consisted of a small $\left(<2 \mathrm{~cm}^{2}\right)$ sensitive area surrounded

bottom (1st stimulus) to top (16th stimulus), and this convention is used in subsequent figures. Note that no impulses were evoked during the static phase of the stimulus for any amplitude of displacement and that increasing the amplitude of skin displacement beyond $0.5 \mathrm{~mm}$ did not elicit more impulses. (Actually, a slight response decrement occurred.) This observation contrasts with those made in each of the other neuronal types encountered and illustrated in subsequent figures. 


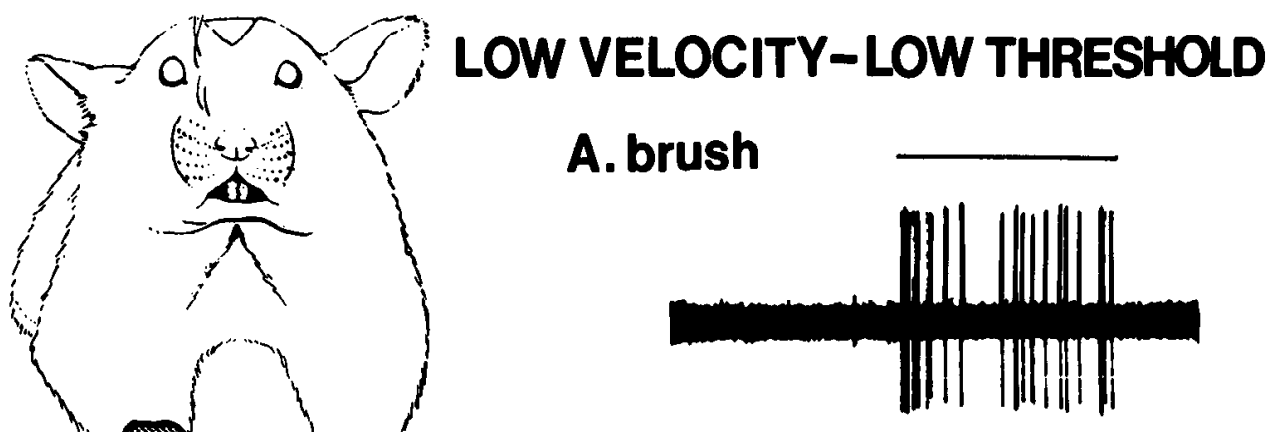

Figure 3. Responses of a low-velocity LT neuron in stratum griseum intermediale to controlled mechanical skin displacement. The receptive field was located on the wrist (stippled area). The neuron responded with a train of impulses to a camel's hair brush moving slowly (represented by the horizontal line) across the receptive field $(A)$. When a vertically indenting ramp stimulus ( 15 $\mu \mathrm{m} / \mathrm{msec}$ ) was delivered, the neuron began to respond once a critical amplitude was reached and continued responding throughout the remainder of the stimulus. This is illustrated in the raster-histogram pairs in $B$ and $C$. A reliable Off response is also apparent here. As shown in $C$, the neuron responded with 1-3impulses to rapid displacement of the skin at an amplitude of $0.5 \mathrm{~mm}$; at higher amplitudes of displacement $(1.5 \mathrm{~mm})$, however, it began to exhibit an after-discharge that extended into the static phase of the stimulus. This was typical of the sample of low-velocity neurons encountered. However, no slowly adapting responses could be evoked at any stimulus amplitudes or velocities.

C.
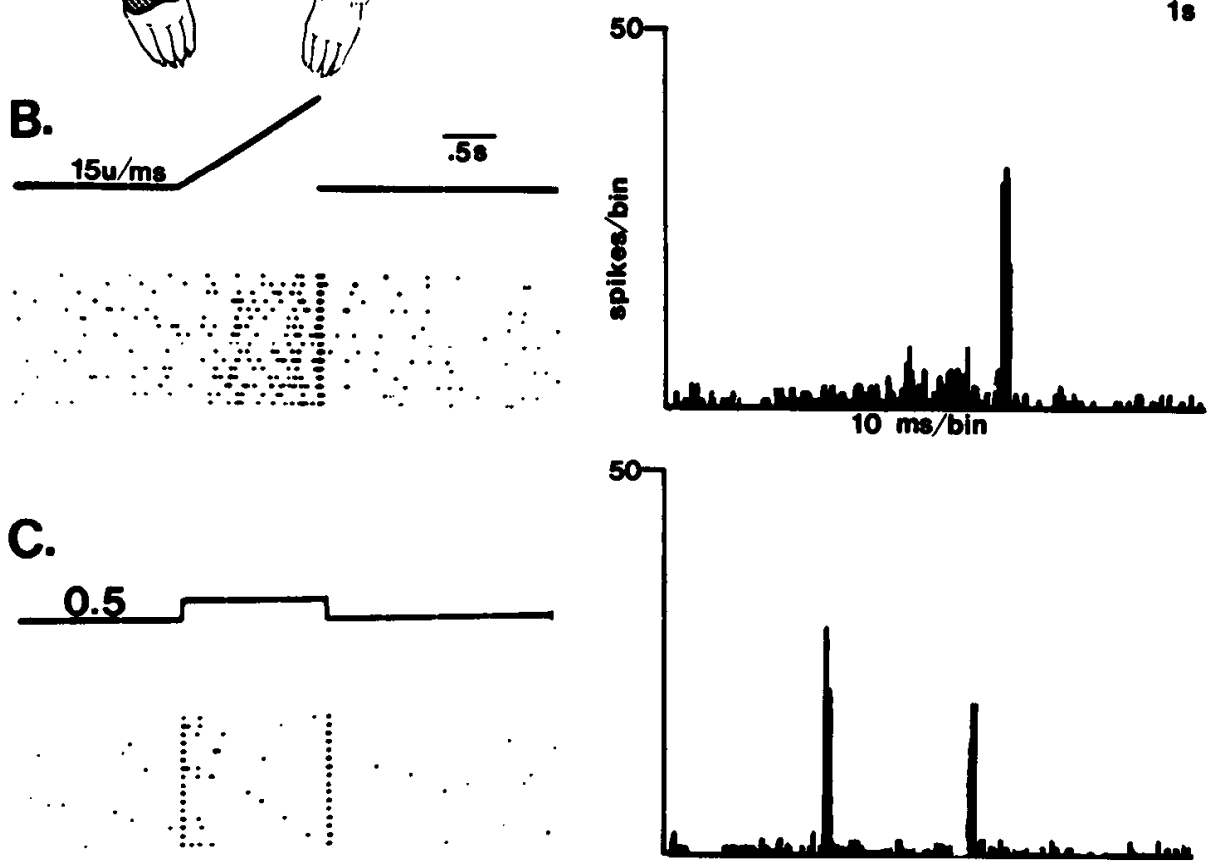

50
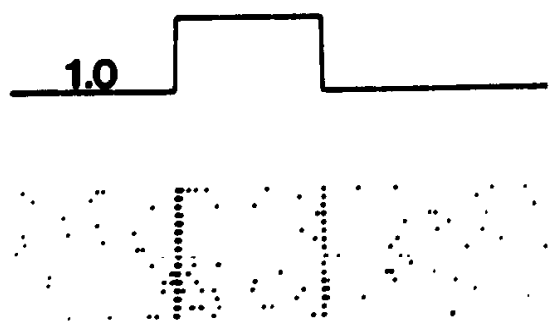

$50-$
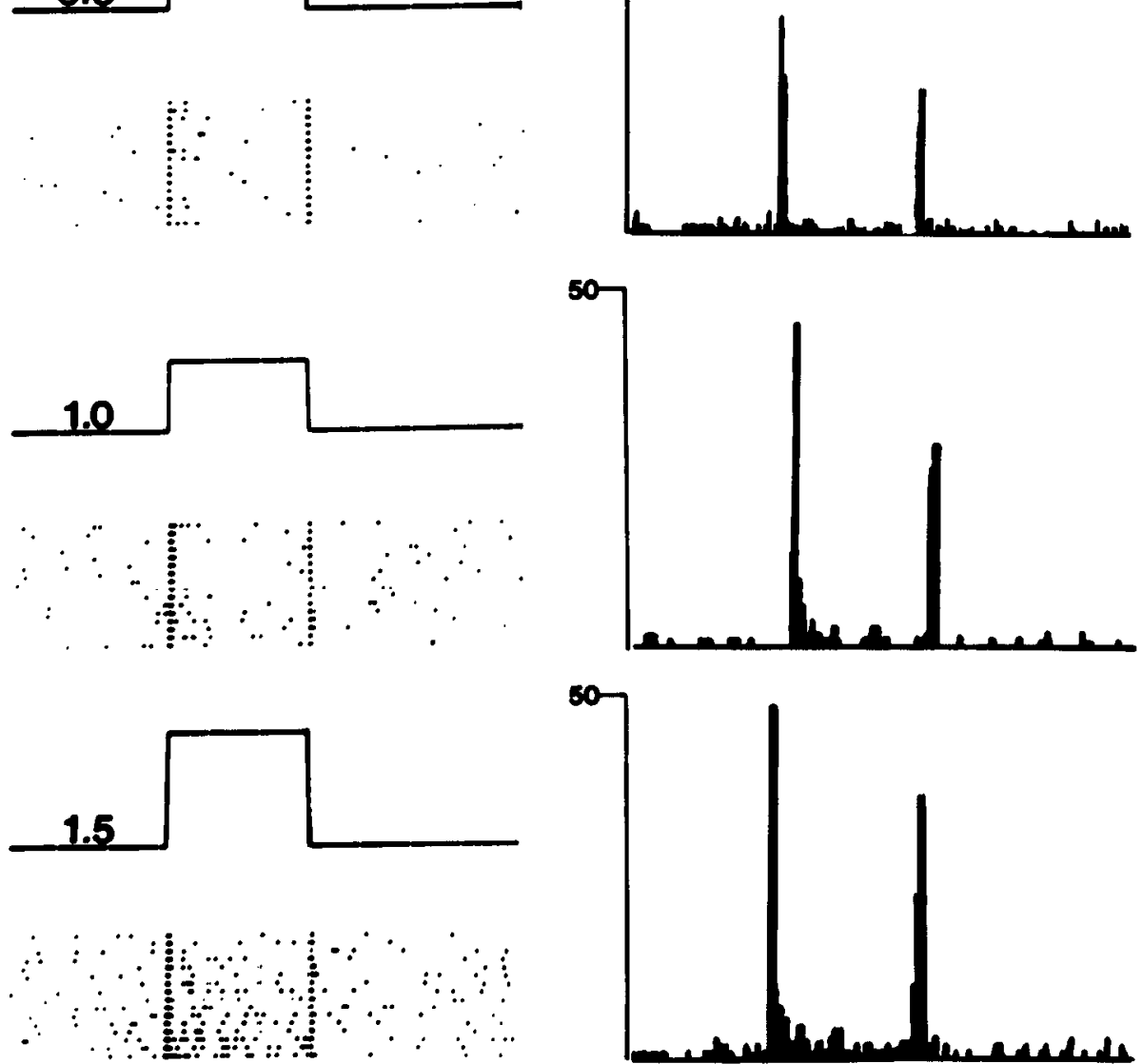

so-

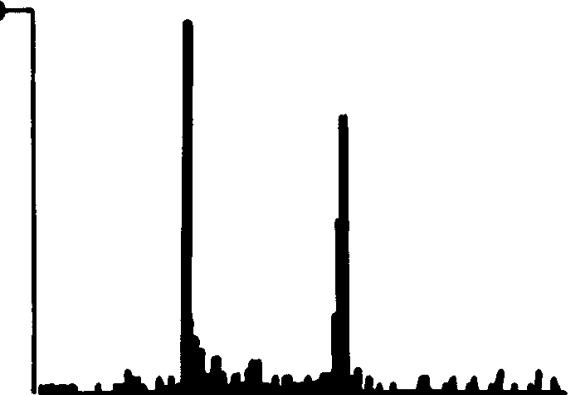




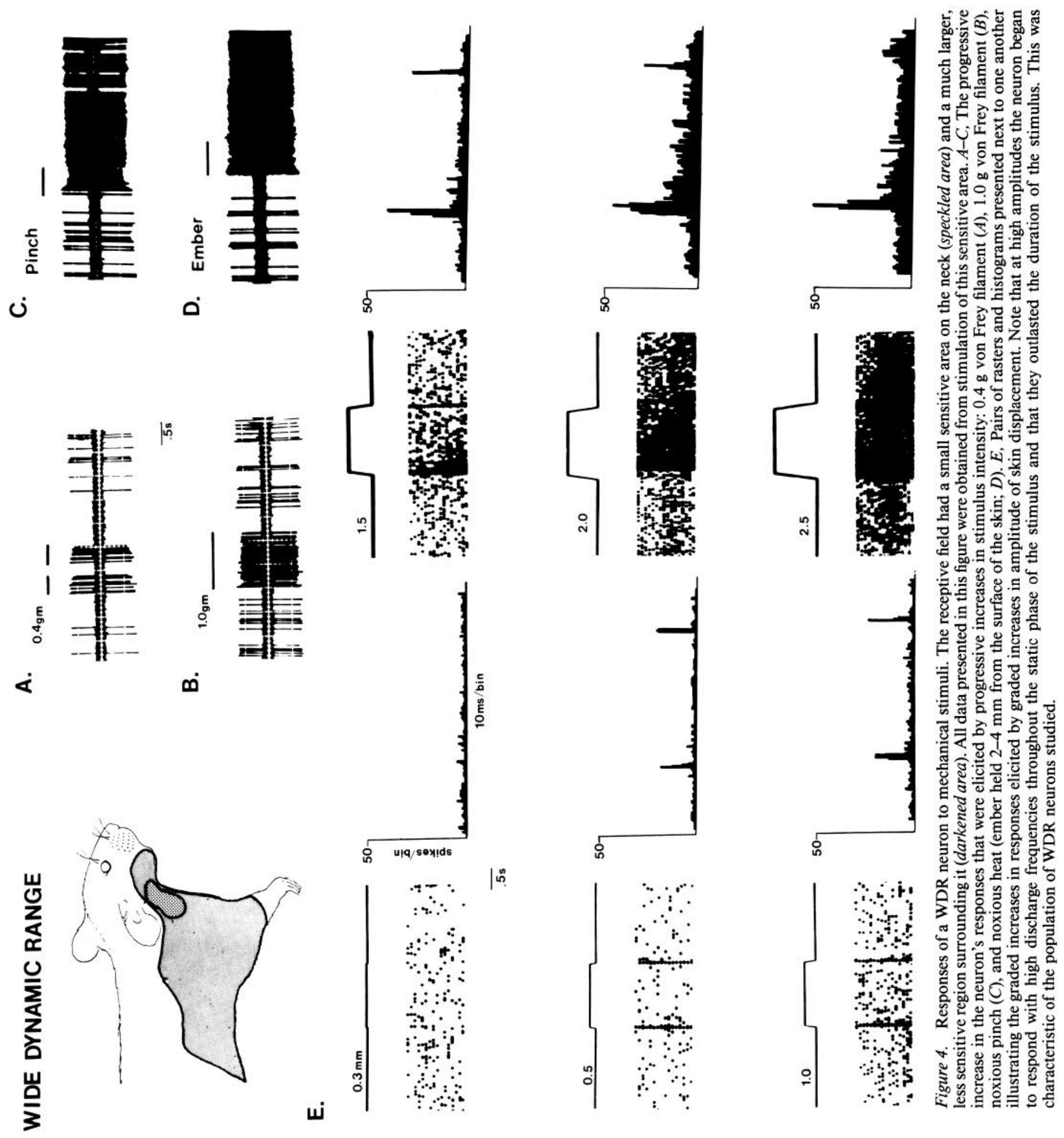


WIDE DYNAMIC RANGE

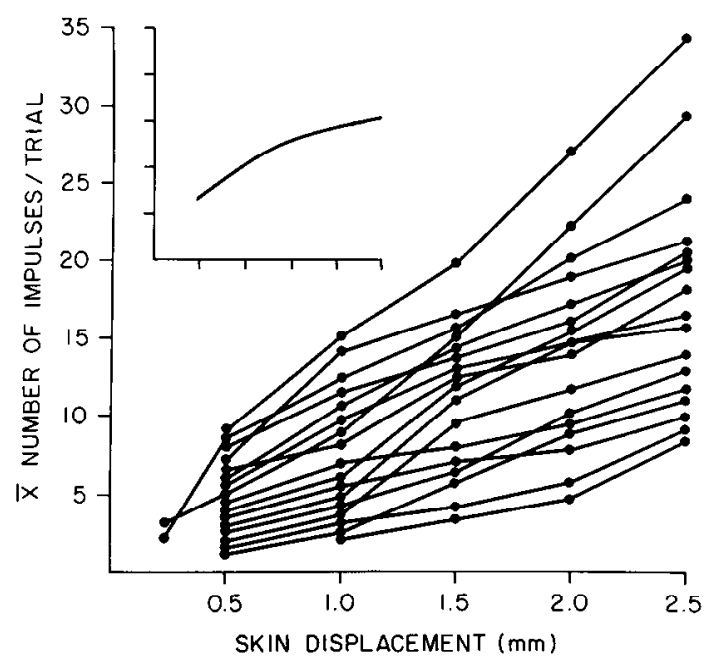

Figure 5. Responses of 17 WDR neurons to graded increases in the amplitude of skin displacement. The magnitude of the response for each neuron, expressed as the number of impulses per $500 \mathrm{msec}$ above spontaneous activity, is plotted against final skin displacement in millimeters. While there was some variability among the individual functions obtained, the population function was a slightly negatively accelerating power function with an exponent of 0.785 . Inset, The statistically derived function for this population is plotted using the same increments along the abscissa and ordinate as on the larger graph. The same convention is followed in subsequent figures.

by a larger, less sensitive peripheral region. It was within this sensitive area that the neurons responded with increasingly higher discharge rates to gentle touch, firm pressure, and noxious pinch. Thus, most of the quantitative data were obtained from this region. The peripheral area had a higher response threshold and required firm pressure and/or frankly noxious stimuli to evoke any response. Neurons having this receptive field organization and responding differentially to innocuous and noxious mechanical and thermal stimuli have been studied extensively in the spinal cord and brain stem (Handwerker et al., 1975; Price and Browe, 1975; Price and Mayer, 1975; Price et al., 1976) and have been classified as WDR neurons. This same classification was applied here.

The responses of 17 WDR neurons to graded increases of innocuous skin displacements were studied in the same manner as were the LT neurons described above. While most $(15 / 17=$ $88 \%$ ) of the WDR neurons responded to controlled mechanical skin displacement of $0.5 \mathrm{~mm}$ or lcss, $2(12 \%)$ requircd amplitudes of only $0.1 \mathrm{~mm}$ to evoke responses. These thresholds were comparable to those of the LT neurons described above. As displacement amplitude increased, WDR neurons exhibited a monotonic increase in the number of impulses evoked. Unlike the LT neurons studied, the responses of WDR neurons were sustained throughout the stimulus application $(1.5 \mathrm{sec})$ and continued for several seconds after terminating the stimulus.

The WDR neuron shown in Figure 4 illustrates the characteristic responses to controlled mechanical skin displacement. This neuron was located in the stratum griseum profundum and had a large receptive field covering the contralateral face, forelimb, and proximal trunk. It had an irregular pattern of spontaneous activity that proved to be a characteristic feature of the population of WDR SC neurons. This feature contrasted with the near absence of spontaneous activity in the other types of nociceptive neurons described below. The neuron had a force threshold of $40 \mathrm{mg}$, and the number of impulses increased with corresponding increases in stimulus force. Skin indentation of $0.5 \mathrm{~mm}$ elicited 1-2 impulses, and as amplitude of displacement increased, the number of impulses also increased. The responses were sustained throughout the stimulus application $(1.5 \mathrm{sec})$, and when high amplitudes $(2.0-2.5 \mathrm{~mm})$ of displacement were uscd, the ncuron's discharges not only were maintained during static displacement but continued for several seconds after the stimulus was terminated. The greatest number of impulses was produced by pinching the skin with toothed forceps or by a noxious thermal stimulus $\left(>45^{\circ} \mathrm{C}\right)$. These noxious stimuli evoked a vigorous and maintained response that often outlasted the stimulus for well over a minute.

Each of the neurons classified as WDR exhibited a monotonic increase in the number of discharges evoked as a function of amplitude of skin displacement. The displacement-response profiles of the 17 WDR neurons studied are illustrated in Figure 5 , and there is some variability among the relationships of individual neurons. The choice of the curve-fitting for these data was based on analysis of covariance and was best described by a slightly negatively accelerating power function (see inset, Fig. 5) with an exponent of $0.785\left(r^{2}=0.994\right)$.

To determine the relationship between the number of impulses evoked and intensity of thermal stimulation, an ascending series of thermal stimuli $\left(42-50^{\circ} \mathrm{C}\right)$ was delivered within the receptive field of the same 17 WDR neurons described above. It was found that each subsequent increase in the intensity of the noxious heat pulse from the baseline temperature (e.g., a shift from $35-44^{\circ} \mathrm{C}$ ) produced a progressive increase in the total number of impulses evoked. The majority $(11 / 17=65 \%)$ of the WDR neurons were sensitive enough to respond to the lowest temperature increment we used (i.e., $35-42^{\circ} \mathrm{C}$ ). The remainder had elevated thermal thresholds and required shifts from 35 to $44^{\circ} \mathrm{C}(5 / 17=29 \%)$ or $35-46^{\circ} \mathrm{C}(1 / 17=6 \%)$.

The responses of the same WDR neuron illustrated in Figure 4 to mechanical stimulation was also studied using an ascending series of noxious thermal stimuli (Fig. 6). Heating the skin from 35 to $42^{\circ} \mathrm{C}$ produced a distinct acceleration in activity, and each additional increase in the intensity of the heat pulse produced corresponding increases in the number of impulses evoked. To determine whether responses to noxious thermal stimuli could have been attributed to a nonspecific effect (i.e., level of arousal or blood pressure), in this and all other neurons, a noxious thermal $\left(50^{\circ} \mathrm{C}\right)$ stimulus was always delivered outside the receptive field as a control. No changes in neuronal activity could be related to control stimulation in this or the other neurons studied.

The stimulus-response relationships of the population of WDR neurons studied with graded thermal stimuli are illustrated in Figure 7. Most of the functions had a slight positive acceleration that was best described by a power function (see inset, Fig. 7) with an exponent of $2.3\left(r^{2}=0.988\right)$.

\section{Nociceptive-specific neurons}

A population of 30 neurons $(30 / 122=25 \%)$ was encountered that also showed responses to noxious stimuli but, unlike WDR neurons, could not be activated by gentle cutaneous stimuli. These neurons had small $\left(<2 \mathrm{~cm}^{2}\right)$ receptive fields and required moderate (1-30 g) to high ( $>30 \mathrm{~g})$ mechanical stimulation for activation; LT stimuli such as brushing, tapping, and gentle skin compression were always ineffective. Neurons responding ex- 


\section{WIDE DYNAMIC RANGE}
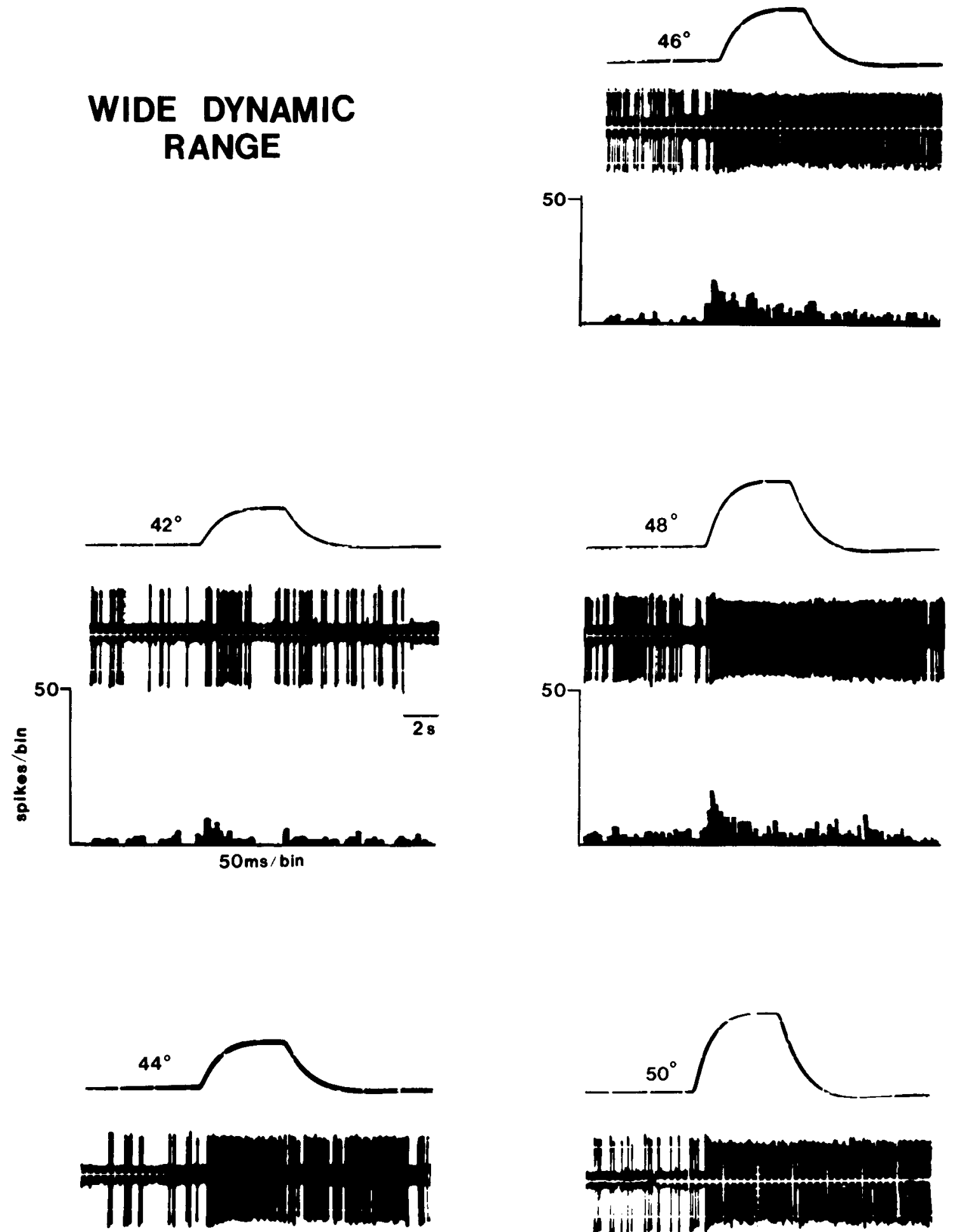
WIDE DYNAMIC RANGE

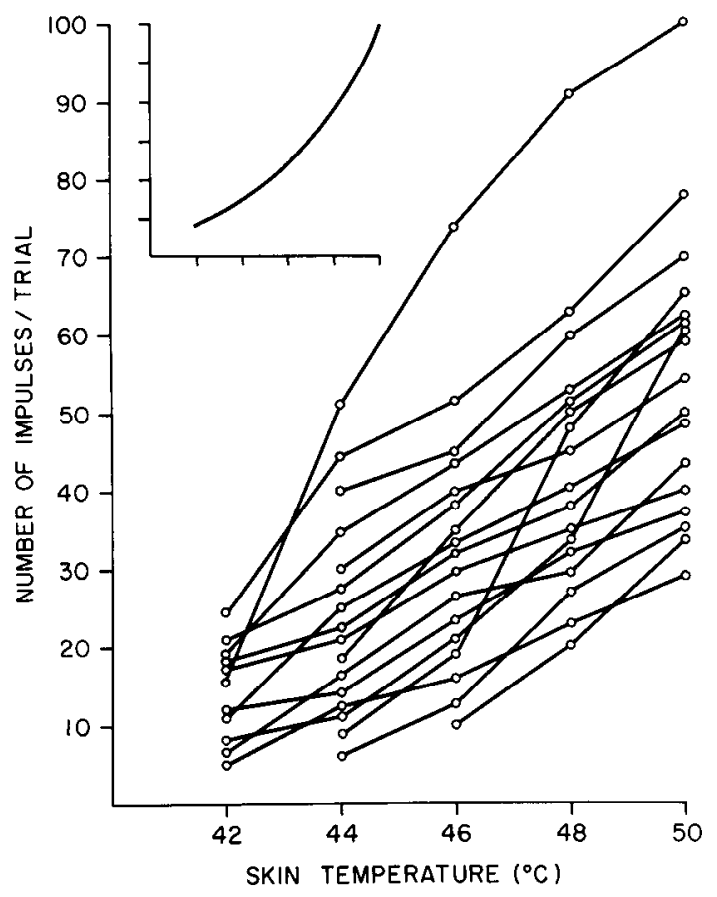

Figure 7. Responses of 17 WDR neurons to graded increases in skin temperature. The magnitude of the response, expressed as the number of impulses in the $5 \mathrm{sec}$ period following the onset of the stimulus, is plotted against skin temperature. The baseline, or adapting temperature, was always $35^{\circ} \mathrm{C}$. Note the similarities in stimulus intensity-response relationships among most of the neurons studied. Most of the relationships obtained were positively accelerating, and the population function was best described by a power function with an exponent of 2.3. Inset, The statistically derived population function.

clusively to noxious stimuli or to intense but non-noxious stimuli have been described in the spinal cord and brain stem as nociceptive-specific (Cervero et al., 1976; Christensen and Perl, 1970; Willis et al., 1974; Price and Browe, 1975; Price and Mayer, 1975; Price et al., 1976), and the same classification (NS) was used here. Two subgroups were encountered: neurons responding both to noxious mechanical and thermal stimuli (NSI, $n=16$ ) and neurons responding exclusively to noxious mechanical stimulation (NSII, $n=14$ ).

All NSI neurons had small receptive fields $\left(<2 \mathrm{~cm}^{2}\right)$, and their receptive field borders were as well-defined as were those of LT neurons. In contrast to both the LT and WDR neurons, however, NSI neurons had elevated force thresholds (1-30 gm, although this remains in the nonpainful range) and longer latencies (11.2-14.0 msec; see Fig. 1) and higher thresholds (>1.0 mA) to electrical stimulation. NSI neurons appeared to respond to both noxious pinch and an ember in the same manner as WDR neurons. The responses of 13 NSI neurons to graded quantitative increases in skin temperature were examined in detail. Like WDR neurons, increasing thermal intensities evoked consistently greater numbers of impulses, as shown in the example illustrated in Figure 8. This NSI neuron had a small receptive field on the face, a force threshold of $6 \mathrm{gm}$, and displayed a maintained discharge to a maintained thermal or mechanical stimulus. Both noxious pinch and noxious heat elicited vigorous responses that outlasted the stimulus, and the number of impulses increased with each increase in intensity.
As was true of WDR neurons, most $(7 / 13=54 \%)$ NSI neurons responded to the lowest skin temperature increments used (35$\left.42^{\circ} \mathrm{C}\right)$. However, several $(5 / 13=38 \%)$ required increments from 35 to $44^{\circ} \mathrm{C}$, and 1 required $35-48^{\circ} \mathrm{C}$. Thermal stimulus-response profiles of the 13 NSI nociceptive neurons are illustrated in Figure 9. The majority of NSI neurons responded monotonically to temperature increments, and the responses were best described by a power function with a slightly steeper slope (2.5) than that shown by WDR neurons. Surprisingly (and as shown in Fig. 10), the stimulus-response relationships for both WDR and NS neuron were strikingly similar. Both are linear when plotted in double-logarithmic coordinates, and their slopes are not significantly different.

NSII neurons differed from other nociceptive SC neurons in that a frankly noxious mechanical stimulus was required to evoke a response; none responded to changes in skin temperature. These neurons had the longest latencies (14.5-16.4 msec; see Fig. 1) to electrical stimulation and required higher current intensities (>2.0 mA). However, the characteristic high-frequency, long-lasting discharge train exhibited by the WDR and NSI neurons also was displayed by NSII neurons in response to noxious mechanical stimulation. NSII neurons had small, well-defined receptive fields.

The responses of a NSII ncuron arc illustratcd in Figure 11. A response was evoked in this and other NSII neurons only when the stimulus force was overtly noxious, and a noxious pinch evoked a vigorous, long-lasting train of discharges. However, responses could not be evoked by thermal stimuli even at the highest temperature increments used $\left(35-50^{\circ} \mathrm{C}\right)$. NSII neurons were difficult to detect since they did not exhibit spontaneous activity and required a noxious mechanical stimulus within a restricted receptive field for activation. Therefore, they may have a higher incidence in the SC than could be determined here.

\section{Additional observations}

A very small population of neurons $(4 / 122=3 \%)$ exhibited spontaneous activity that was suppressed by either a gentle tactile $(2 / 4)$ or a noxious $(2 / 4)$ stimulus. The receptive fields of these neurons were small $\left(<2 \mathrm{~cm}^{2}\right)$, and all demonstrated a regular pattern of spontaneous activity. In those neurons suppressed by innocuous tactile stimuli, the inhibition lasted as long as the stimulus was maintained. In contrast, those neurons inhibited by a brief noxious pinch were inhibited for up to a minute after the pinch. The response latencies to electrical stimulation for those neurons whose activity was suppressed by gentle tactile stimuli were short $(5.4$ and $6.0 \mathrm{msec}$, see Fig. 1) compared to neurons whose spontaneous activity was inhibited by noxious pinch (10.0 and $10.2 \mathrm{msec}$ ). Examples of each type of neuron are illustrated in Figure 12.

\section{Distribution of cell types}

The recording sites for the 55 nociceptive SC neurons are shown on a drawing of transverse sections of the SC in Figure 13. Nociceptive neurons were distributed throughout the rostralcaudal two-thirds of the SC and across most of its medial-lateral extent. Although nociceptive neurons were found equally distributed among the intermediate and deep laminae, there was a partial lamina segregation of 1 class of nociceptive cells. WDR and NSI neurons were nearly evenly distributed in intermediate and deep laminae, but the majority $(12 / 14)$ of NSII neurons were located in the deep laminae. 

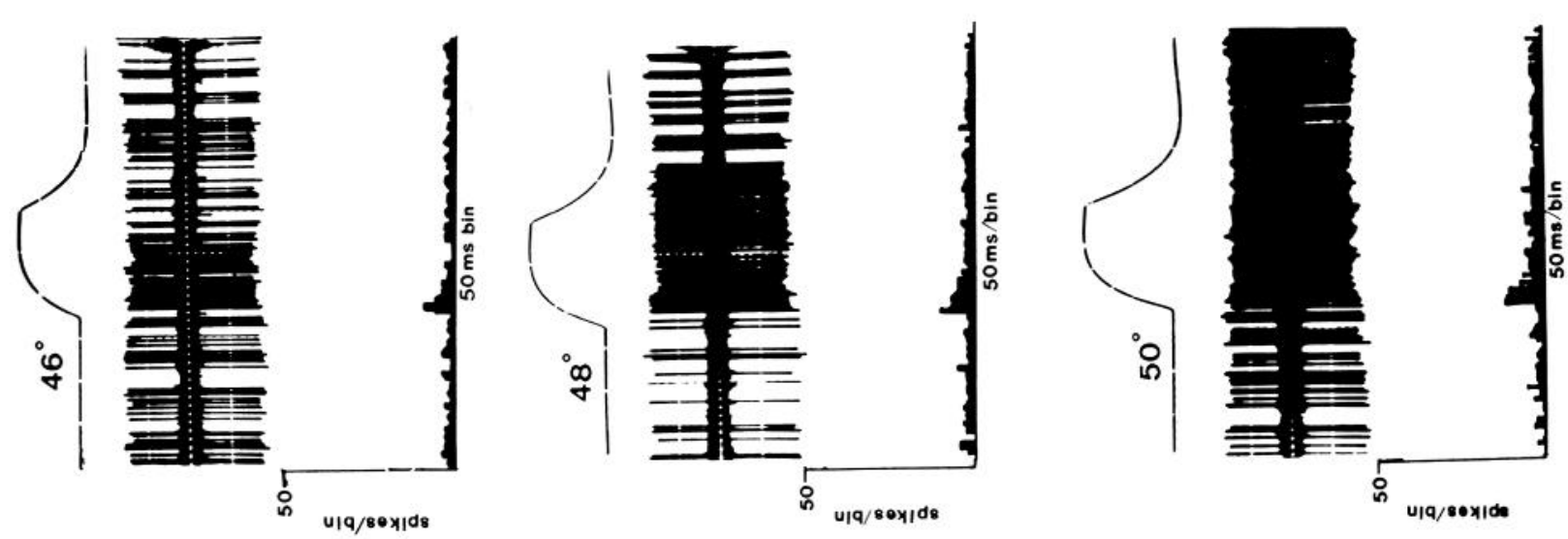

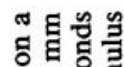

芭出总

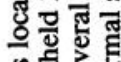

象密

물 हृ워

称

믈

8

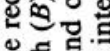

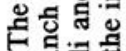

-

实

के

.
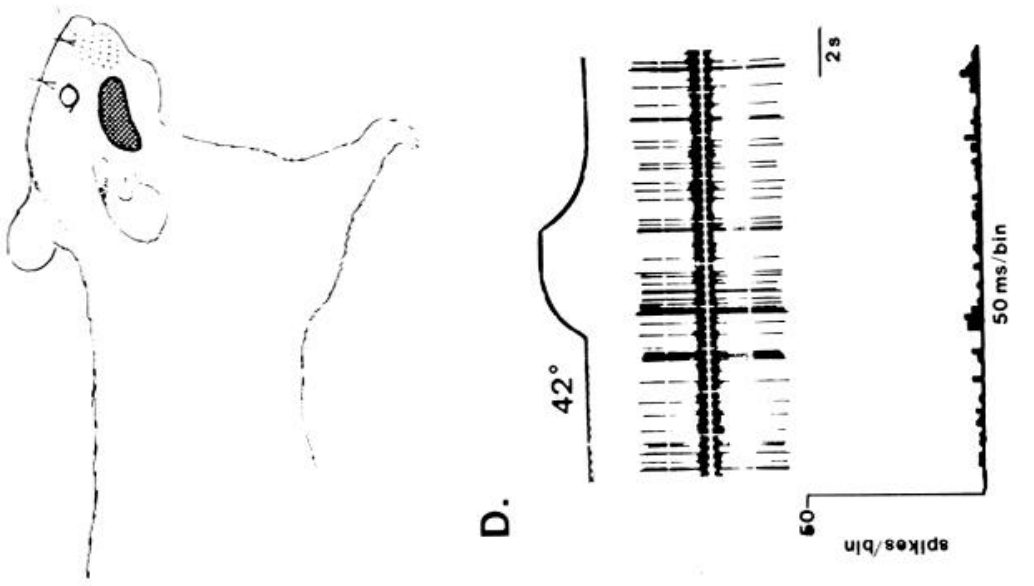

월

월

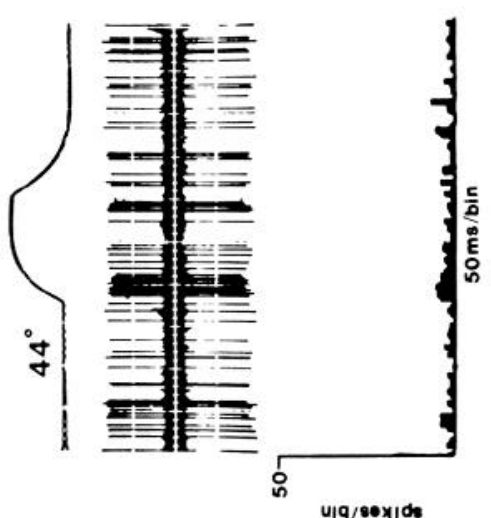

믕

슬

घ 응

을

รับ

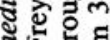

空至

웡

on.

so

을 늘

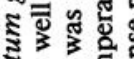

啳它
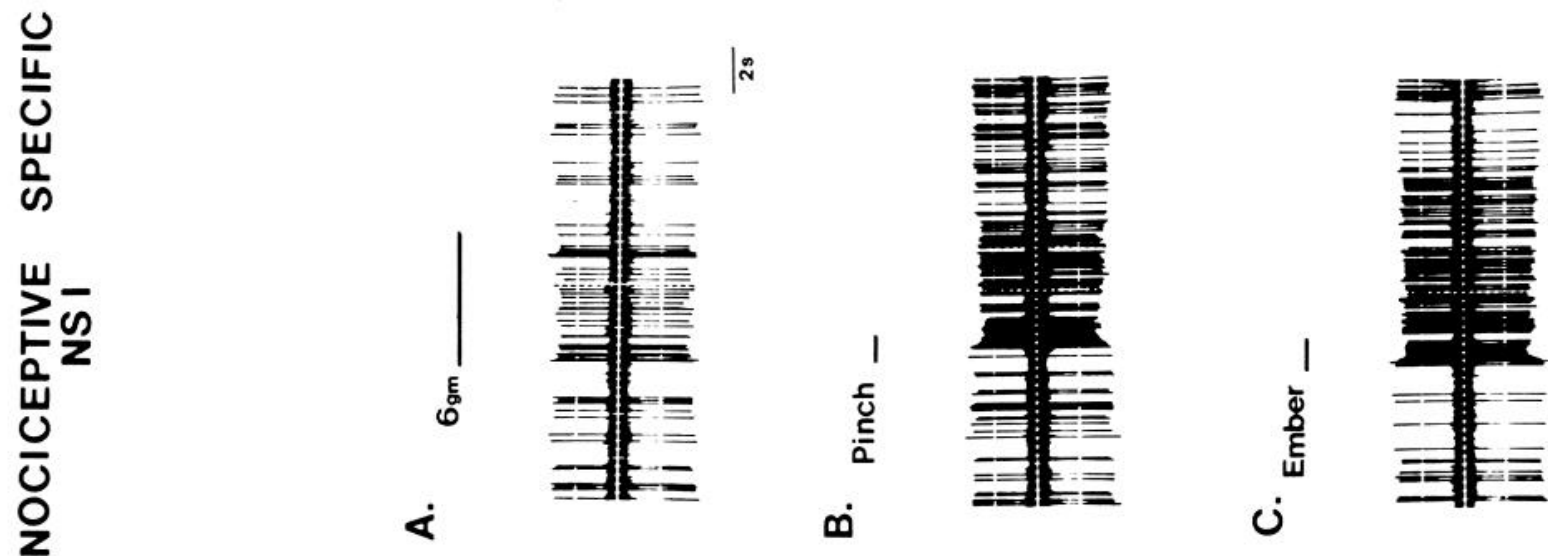

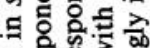

대원ㅎ․

光它递

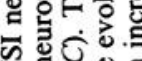

乙过

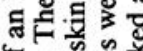

¿

密

论

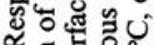

도롱ํㅇ

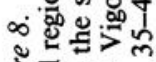

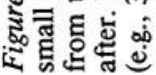


NOCICEPTIVE SPECIFIC (NSI)

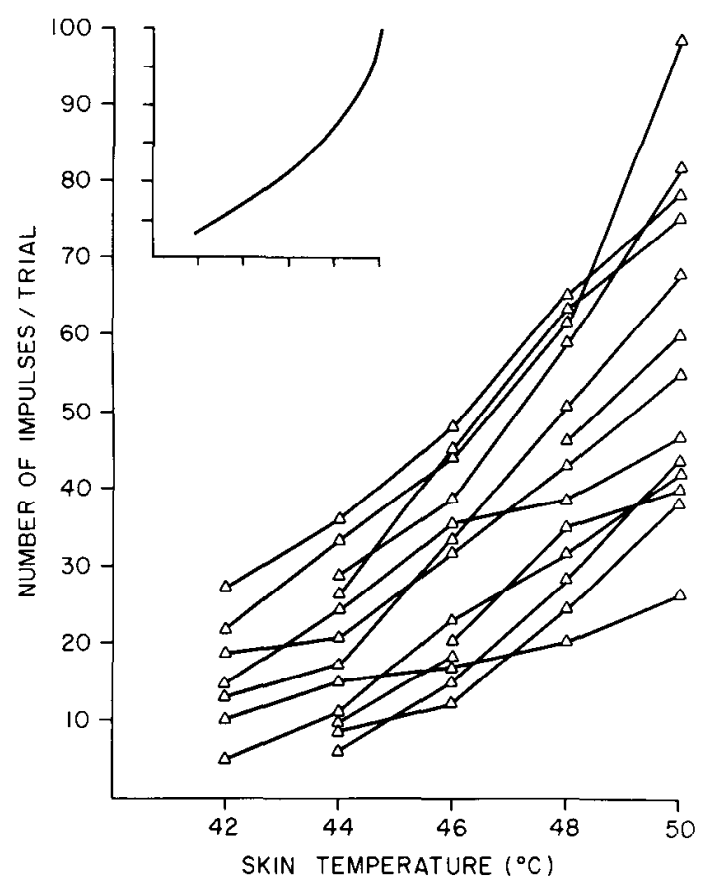

Figure 9. Responses of 13 NSI neurons to graded increases in skin temperature. The magnitude of the response, expressed as the number of impulses in the $5 \mathrm{sec}$ period following the onset of the stimulus, is plotted against skin temperature. Note the similarities in stimulus intensity-response relationships among most of the NSI neurons studied. The relationships were positively accelerating, and the population function was best described by a power function with an exponent of 2.5. Inset, The statistically derived function.

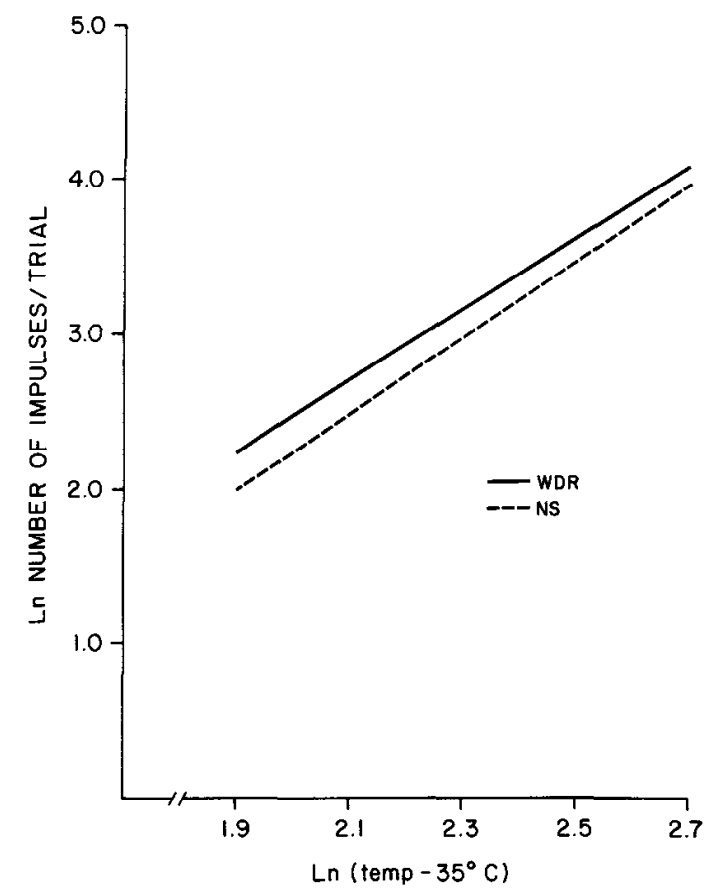

Figure 10. Comparison of the statistically derived population functions of WDR and NSI neurons to noxious thermal stimuli. The statistically derived functions illustrated in the insets of Figures 7 and 9 are replotted here using a double-logarithmic plot (base $e$ ) and demonstrate the striking similarities between the WDR ( $\longrightarrow$ ) and the NSI $(--)$ neurons. An $F$ test comparison failed to show any significant differences.

\section{NOCICEPTIVE SPECIFIC} NS II

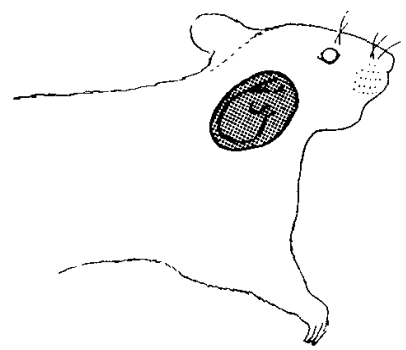

A. $75 \mathrm{gm}$

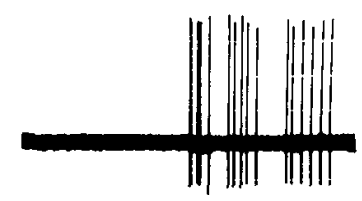

B. PINCH

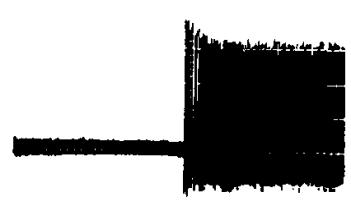

C. $50^{\circ}$

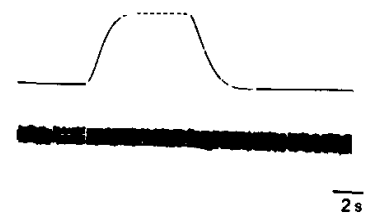

Figure 11. Responses of a NSII neuron to noxious mechanical stimulation. The receptive field was located on the pinna, and the neuron was located in the stratum griseum profundum. The neuron had a highintensity mechanical threshold and required a $75 \mathrm{~g}$ von Frey filament $(A)$ or a noxious pinch $(B)$ to elicit responses. This high mechanical threshold, coupled with the absence of responsiveness to any shifts in skin temperature $(C)$, even those well into the noxious range (i.e., 35$50^{\circ} \mathrm{C}$ ), characterized the NSII population.

\section{INHIBITORY}

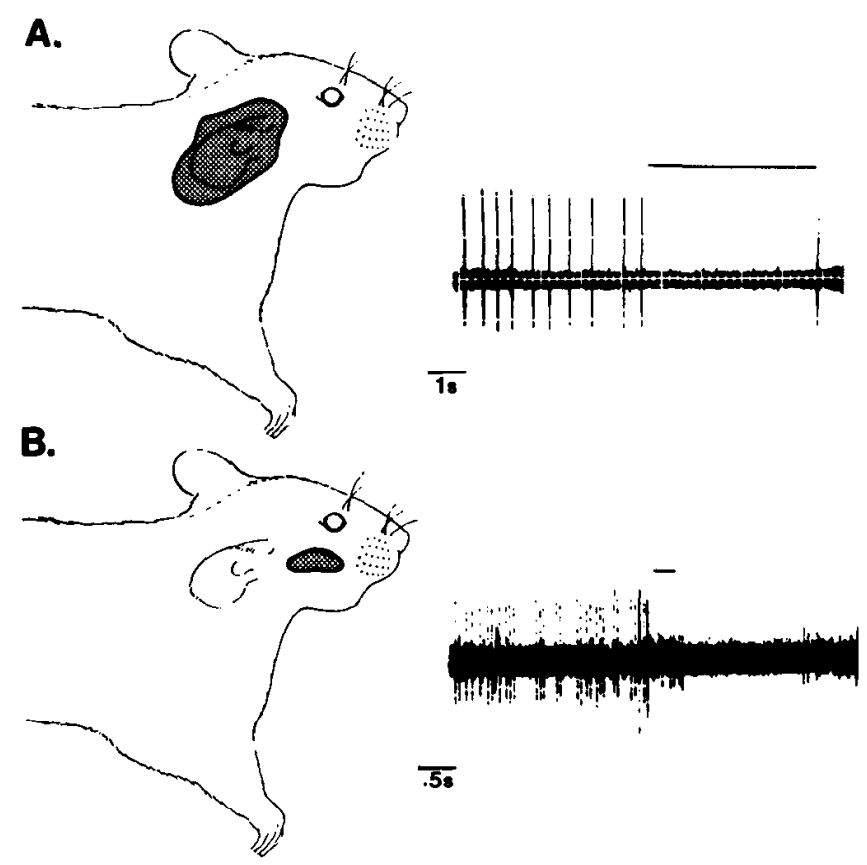

Figure 12. Response characteristics of $2 \mathrm{SC}$ neurons whose spontaneous activity was eliminated by stimulation of the skin. $A$, The low rate of ongoing spontaneous activity of a neuron located in the stratum griseum profundum was suppressed by lightly touching the pinna and the small area surrounding it (darkened area) with a cotton swab. Its activity resumed when the tactile stimulus was removed. $B$, Record from a neuron located in stratum griseum profundum that exhibited a high rate of spontaneous activity that was unaffected by gentle tactile stimuli. However, noxious pinch of the skin within a limited area (darkened area) produced an abrupt cessation of ongoing activity that outlasted the stimulus for approximately $1 \mathrm{~min}$. 


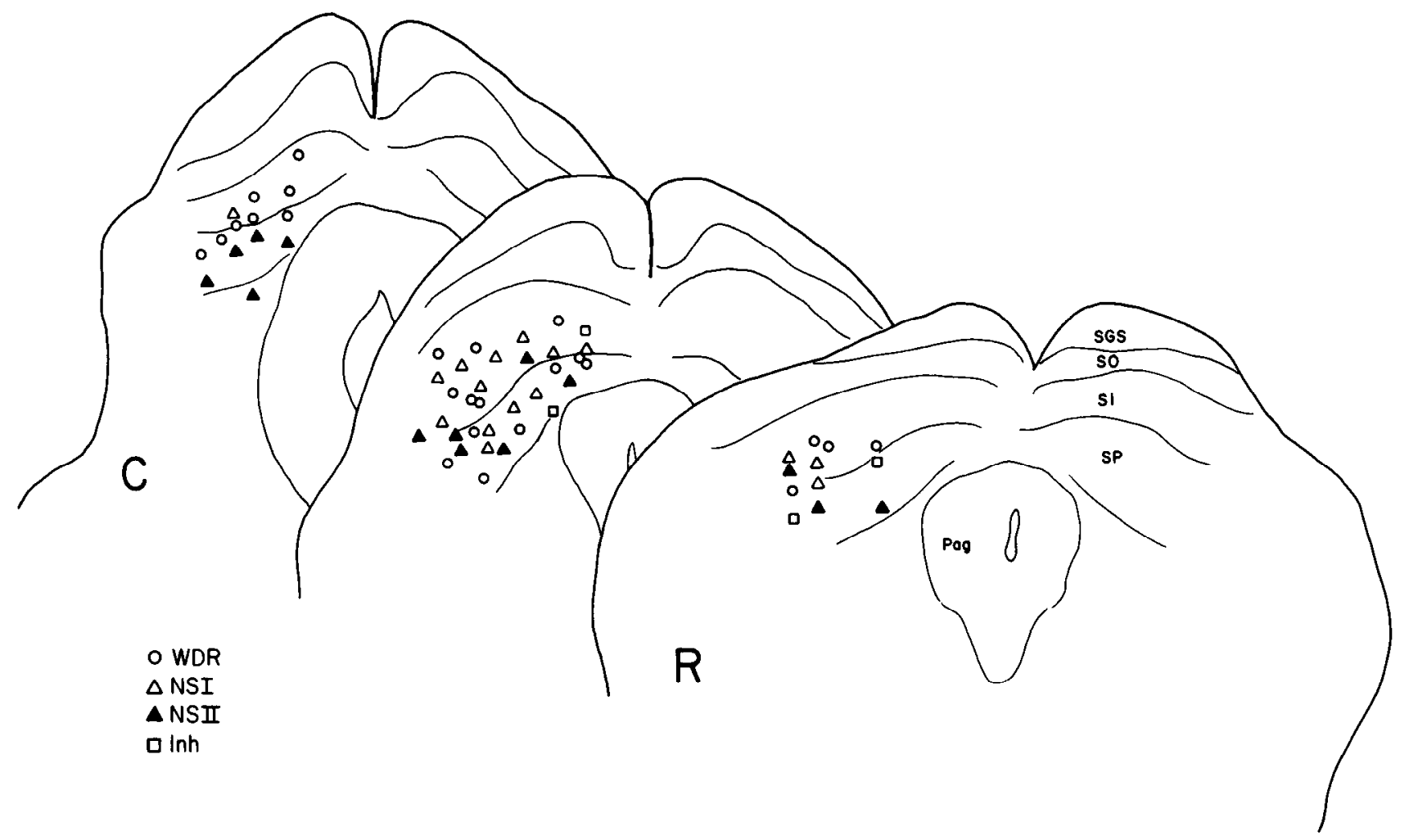

Figure 13. Locations of WDR $(0)$, NSI $(\Delta)$, NSII $(\Delta)$, and Inh $(\square)$ neurons in the SC. Each symbol represents the locus of a single neuron from which quantitative data were obtained. The locations of neurons in the schematic drawings of the midbrain were determined by histological reconstruction of electrode tracks. Note the marked tendency for clustering of NSII neurons in the deepest aspects of the SC. Sections are arranged in the rostral $(R)$-caudal $(C)$ direction in approximately $0.5 \mathrm{~mm}$ steps. SGS, stratum griseum superficiale; SO, stratum opticum; SI, strata griseum and album intermedium; SP, strata griseum and album profundum; Pag, periaqueductal gray.

\section{Discussion}

In the present study the receptive field features of somatosensory SC neurons were evaluated, and their response properties were examined quantitatively using controlled innocuous and noxious mechanical and thermal stimuli. The majority of neurons in the intermediate and deep laminae of the SC were activated optimally by innocuous forms of mechanical stimuli and responded only during the movement component of the stimulus. Such neurons were classified as LT, to be consistent with the classification of first-order afferents with similar response properties (see Results). In addition to these LT mechanoreceptive neurons, however, several distinct types of nociceptive neurons similar to those found elsewhere in the nervous system were encountered (WDR and NS). WDR neurons responded with progressive increases in the number of discharges elicited to increases in stimulus intensity and thus appear capable of transmitting information about both light tactile and painful stimuli. NS neurons, on the other hand, had small, well-defined receptive fields and responded only to intense mechanical and thermal stimulation. The high incidence of SC neurons capable of encoding the spatial and intensity properties of noxious stimuli makes it likely that this midbrain structure plays a role in nociception.

\section{LT neurons}

A large number of somatosensory structures project to the SC, including the dorsal horn (rodent: Antonetty and Webster, 1975; Rhoades, 1981a; cat: Baleydier and Mauguiere, 1978; Edwards et al., 1979; Nagata and Kruger, 1979); the spinal trigeminal complex (rodent: Stewart and King, 1963; Feldman and Kruger, 1980; Killackey and Erzurumlu, 1981; Rhoades, 1981a; Huerta et al., 1983; Bruce et al., 1984; McHaffie et al., 1984; cat: Baleydier and Mauguiere, 1978; Edwards et al., 1979; Nagata and Kruger, 1979; Ogasawara, 1981; McHaffie et al., 1986); the lateral cervical nucleus (rodent: Torvik, 1956; Lund and Webster, 1967b; Rhoades, 1981a; cat: Baleydier and Mauguiere, 1978; Blomqvist et al., 1978; Craig and Tapper, 1978; Edwards et al., 1979; Flink et al., 1983), the dorsal column nuclei (rodent: Lund and Webster, 1967a; Rhoades, 1981a; cat: Hand and van Winkle, 1977; Baleydier and Mauguiere, 1978; Berkley and Hand, 1978; Blomqvist et al., 1978; Nagata and Kruger, 1979; Cooper and Dostrovsky, 1985); and the somatosensory cortex (rodent: Killackey and Erzurumlu, 1981; Rhoades, 1981a; cat: Wise and Jones, 1977; Kawamura and Konno, 1979; Clemo and Stein, 1982, 1983; Huerta and Harting, 1983; Stein et al., 1983). Yet the responses of LT neurons in the SC still have many features characteristic of first-order afferents.

SC LT neurons responded only during the movement component of skin displacement and were thus rapidly adapting. No slowly adapting LT cells were encountered anywhere in the SC. The majority of LT cells responded only to high-velocity displacement of the skin and demonstrated little linear directionality; that is, they responded with about equal sensitivity to inward movements (On) and return to initial position (Off). A smaller proportion of LT neurons were activated by lower velocities and were more sensitive to On than to Off. Similar properties have been described as characteristic of low- and 
high-velocity, rapidly adapting hair and field primary afferents (Brown and Iggo, 1967; Chambers et al., 1972; Burgess, 1973; Burgess et al., 1974; Horch et al., 1977). It is interesting to note that the velocities necessary to activate many SC LT neurons often were much higher than usually reported for first-order cutaneous mechanoreceptors. It is not yet clear whether this difference results from the convergence of various tectopetal afferents or a skewed input from first-order afferents at the upper end of their velocity range. The somatotopic organization of these LT neurons undoubtedly underlies the ability of the SC to facilitate localization of gentle tactile stimuli (see Ingle and Sprague, 1975).

\section{Nociceptive neurons: physiological properties}

The primary aim of the present study was to characterize the receptive field features and response properties of SC neurons previously shown to respond to noxious stimuli (Stein and Dixon, 1978). The possibility that noxious stimuli might evoke responses due to changes in general arousal was of concern. However, that the responses of nociceptive SC neurons did not result from a generalized arousal reaction is indicated by (1) the well-defined borders of their receptive fields and the ineffectiveness of noxious stimuli outside these borders, (2) the close intermixing of LT and nociceptive neurons within the SC, (3) the activation and suppression of neighboring neurons by the same noxious stimulus, and (4) the regular increase in the number of impulses evoked by progressive increases in stimulus intensity. Rather, each of the 3 types of nociceptive neurons encountered in the $\mathrm{SC}$ had response properties remarkably like nociceptive neurons described in the spinal cord and medullary dorsal horn, which are thought to play primary roles in nociception.

\section{WDR neurons}

WDR neurons are classified as such in spinal cord (Menetrey et al., 1977; Price et al., 1978, 1979; Kenshalo et al., 1979), medullary dorsal horn (Gordon et al., 1961; Price et al., 1976; Yokota and Nishikawa, 1977; Yokota, 1983), thalamus (Guilbaud et al., 1980; Kenshalo et al., 1980), and cortex (Lamour et al., 1982, 1983; Kenshalo and Isensee, 1983) because they respond to noxious mechanical or noxious thermal stimulation with a discharge frequency that is higher than that which can be elicited by any form of innocuous stimulation. All have force thresholds less than $1 \mathrm{~g}$, and often less than $100 \mathrm{mg}$. The receptive fields of WDR neurons vary in size but are usually much larger (except those in thalamus) than those of primary afferents. They are often organized into central zones in which the neuron responds with increasingly higher discharge frequencies to gentle touch, firm pressure, and noxious pinching. These central zones are surrounded by less sensitive zones where firm pressure and noxious stimuli are required to evoke discharges. At the spinal level, this receptive field organization has been thought to be one of the spatial factors important for the transmission of nociceptive information (Price et al., 1978). Since the area sensitive to noxious stimuli is much larger than that sensitive to innocuous stimuli, a noxious mechanical stimulus is likely to activate a larger number of receptors and central projecting neurons than a light tactile stimulus applied to an equal area of skin. This spatial mechanism appears to be maintained intact at the level of the SC. In fact, each of the response properties that characterizes WDR neurons in spinal cord and medullary dorsal horn is also typical of WDR neurons in SC.
One feature of WDR neurons, regardless of where they are found, is that brief noxious stimuli will evoke a prolonged train of discharges. This parallels human psychophysics in that the same stimuli evoke temporal summation and aftersensations (Price, 1972; Price and Browe, 1975; Price et al., 1976, 1977, 1979; Price and Dubner, 1977) with similar time courses. Some innocuous stimuli also evoke prolonged afterresponses in WDR neurons (Mclzack and Eiscnberg, 1968; Price et al., 1979), presumably accounting for innocuous cutaneous aftersensations. Prolonged afterdischarges are characteristic of WDR neurons in the $\mathrm{SC}$ as well, but the most striking similarity among WDR neurons of the $\mathrm{SC}$ and elsewhere is in their responses to noxious thermal stimuli. The stimulus-response relationships among all WDR populations is positively accelerating and is described by a power function (Price et al., 1978; Kenshalo et al., 1979; Peschanski et al., 1980). For dorsal horn and SC WDR neurons the stimulus-response function is best described by a power function with an exponent of 2.3. This same power function closely parallels human psychophysical magnitude estimates in the same temperature range, and it is unlikely that the close correspondence of the neural and psychophysical functions is coincidental (see Price et al., 1983). Yet, it is premature to conclude that the $\mathrm{SC}$ plays a role in subjective magnitude estimation, for there are no experimental data indicating whether removal of the SC has any effect on such judgments.

Stimulus-response relationships for mechanoreceptive neurons in hairy skin have been described by negatively accelerating power functions (Werner and Mountcastle, 1965) with exponents ranging between 0.35 to 0.75 (Harrington and Merzenich, 1970, but also see Willis et al., 1975). Psychophysical functions of the same general shape have been described in hairy skin of man (Harrington and Merzenich, 1970). For SC WDR neurons the stimulus-response relationships were best described by a slightly negatively accelerating power function with an exponent of 0.785 , and they were therefore within the range described for primary afferent units.

\section{NS neurons}

Neurons that respond exclusively to noxious stimuli were found deep in the SC. Similar neurons have been found in the spinal cord and medullary dorsal horn (Christensen and Perl, 1970; Willis et al., 1974; Price et al., 1976, 1978, 1979; Kumazawa and Perl, 1978; Kenshalo et al., 1979), as well as in thalamus (Gaze and Gordon, 1954; Perl and Whitlock, 1961; Mitchell and Hellon, 1977; Guilbaud et al., 1980) and cortex (Lamour et al., 1982, 1983; Kenshalo and Isensee, 1983). Two categories of NS neurons are found in SC and clscwhere. The NSI neurons respond to firm nonpainful pressure of the skin but respond with a higher discharge frequency to tissue-damaging stimuli (mechanical and thermal). The second type of NS (NSII) responds only to frankly noxious mechanical stimuli, such as pinching the skin with a toothed forceps.

Regardless of their location in the CNS, NS neurons have small, well-defined receptive fields. Because of their modality specificity and small receptive fields, NS neurons are thought to be well suited to provide information about the location and type of a noxious stimulus. Some investigators have observed that NS neurons have a "flatter" stimulus-response function than do WDR neurons to increasing stimulus intensities (Hoffman et al., 1981; Bushnell et al., 1984). As a consequence of this difference, it was postulated that WDR neurons are better suited for determining stimulus intensity in the noxious range 
than are NS neurons. However, other investigators have not noted differences in spinal cord, thalamus, or cortex (Kenshalo et al., 1979, 1980; Kenshalo and Isensee, 1983). We found no such difference in the response properties of the nociceptive cell types in the SC.

\section{Possible sources of nociceptive input to the SC}

Many of the somatosensory pathways that convey tactile information to the SC from the spinal cord may carry information about noxious stimuli as well. In the rodent, these include direct projections from the dorsal horn (Antonetty and Webster, 1975; Menetrey et al., 1977; Rhoades, 1981a) and lateral cervical nucleus (Torvik, 1956; Lund and Webster, 1967b; Rhoades, 1981a). In the rat, a direct spinotectal projection arises from neurons in the contralateral lamina I, where NS neurons are located, as well as from lamina V, where WDR neurons are located (Menetrey et al., 1975). In the hamster there is also evidence that lamina IV WDR neurons project directly to the SC (Rhoades, $1981 \mathrm{~b})$. In addition, the lateral cervical nucleus in the rat is known to contain WDR neurons (Giesler et al., 1979) and projects to the SC in hamster as well (Rhoades, 1981a).

The high incidence of both WDR and NS neurons on the face may reflect a direct nociceptive input via the trigeminotectal projection (Stewart and King, 1963; Killackcy and Erzurumlu, 1981; Rhoades, 1981 a; Bruce et al., 1984; McHaffie et al., 1984) known to terminate in the rostral portion of the deep laminae, where many nociceptive neurons on the face were found. The trigeminotectal projection is substantial in both hamster and rat, and arises mainly from neurons in subnucleus interpolaris but also from other subdivisions of the complex. While there are few physiological data about the representation and distribution of nociceptive trigeminal neurons in rodent, NS and WDR neurons are known to be distributed throughout the cat spinal trigeminal complex (Eisenman et al., 1963; Khayyat et al., 1975; Sessle and Greenwood, 1976; Hu and Sessle, 1979; Hayashi et al., 1984). Thus, the ascending inputs alone appear to be sufficient to supply SC neurons with WDR and NS properties. Yet, the substantial input known to be derived from somatosensory cortex also may contribute to this representation. Descending projections from ipsilateral SI and SII cortex have been described in rodents (Wise and Jones, 1977; Killackey and Erzurumlu, 1981; Rhoades, 1981a; Rhoades et al., 1981) and noxious stimuli result in neuronal responses in these areas (Isseroff et al., 1982; Lamour, 1982, 1983).

\section{Distribution of WDR and NS neurons}

While all nociceptive neurons were located in the deeper laminae of the SC, the subtypes did exhibit a partial laminar distribution. WDR and NSI neurons were found equally distributed in the intermediate and deep laminae. However, NSII neurons were nearly all clustered in the deepest aspects of the SC. Spatial segregation among WDR and NS neurons has been reported for trigeminal neurons in subnucleus caudalis (Yokota and Nishikawa, 1977; Yokota, 1983) and for thalamic neurons in nucleus ventralis posterior medialis (Yokota and Matsumoto, $1983 a, b)$. Perhaps the spatial segregation of these subtypes reflects a functional segregation based on inputs and outputs. In this regard, subnucleus caudalis projects preferentially to the deep laminae of the SC (Bruce et al., 1984), and differential laminar distributions of afferents (tectospinal, tecto-oculomotor, tecto-olivary, and tectoparalemniscal projections) have been noted in all species studied (Graham, 1977; Edwards and Hen- kel, 1978; Henkel and Edwards, 1978; Huerta and Harting, 1984).

\section{Functional considerations}

One popular theory divides pain into 2 components: a sensorydiscriminative component and motivational-affective component (Melzack and Casey, 1968). The ability to identify the quality and the spatial, temporal, and intensity aspects of a noxious stimulus are attributes of the sensory-discriminative component, while the unpleasant aspects of the stimulus, which lead to avoidance and escape reactions, reflect the motivational-affective component. Spinal cord and medullary dorsal horn WDR neurons are known to activate central mechanisms related to the affective-motivational component of pain, as well as the central mechanisms related to sensory-discrimination (Mayer et al., 1975; Price and Dubner, 1977). Each of the physiological characteristics necessary for neurons to play a part in these components of pain is also present in WDR neurons of the SC. In the present experiments, NS and WDR neurons of the $\mathrm{SC}$ were indistinguishable in their encoding of stimulus intensity in the noxious range. However, the small receptive field size and modality-specific properties of NS neurons make them significantly better candidates to encode stimulus location and submodality than the WDR neurons. Together, these 2 neuronal types can readily serve the complementary roles of detecting stimulus modality and location as well as the intensity of stimulus.

Although SC neurons exhibit all the features of nociceptive neurons in structures known to be involved in nociception, the exact role of the $\mathrm{SC}$ in this function is not clear. It is reasonable to suggest that there is significant survival value in enabling potentially harmful stimuli to have access to a structure involved in alerting and orienting an animal to peripheral stimuli. The results of the present experiment, along with the observations that lesions to the deep laminae of the SC produce inattention and maladaptive responses (Sprague and Meikle, 1965; Casagrande et al., 1972; also see Sprague et al., 1961) to some noxious stimuli, appear to support this postulation and lend credence to the early belief that pain is integrated at 3 levels of the neuraxis: cortex, thalamus, and tectum mesencephali (Walker, 1943).

\section{References}

Allon, N., and Z. Wollberg (1978) Responses of cells in the superior colliculus of the squirrel monkey to auditory stimuli. Brain Res. 159: 321-330.

Antonetty, C. M., and K. E. Webster (1975) The organization of the spinotectal projection. An experimental study in the rat. J. Comp. Neurol. 163: 449-466.

Baleydier, C., and F. Mauguiere (1978) Projections of the ascending somesthetic pathways to the cat superior colliculus visualized by the horseradish peroxidase technique. Exp. Brain Res. 31: 43-50.

Berkley, K. J., and P. J. Hand (1978) Efferent projections of the gracile nucleus in the cat. Brain Res. 153: 262-283.

Bessou, P., and E. R. Perl (1969) Response of cutaneous sensory units with unmyelinated fibers to noxious stimuli. J. Ncurophysiol. 32: 1025-1043.

Bishop, P. O., W. Burke, and R. David (1962) Single unit recordings from antidromically activated optic radiation neurons. J. Physiol. (Lond.) 162: 363-389.

Blomqvist, A., R. Flink, D. Bowsher, S. Griph, and J. Westman (1978) Tectal and thalamic projections of dorsal column and lateral cervical nuclei: A quantitative study in the cat. Brain Res. 141: 335-341.

Bromberg, M. B., and D. Whitehorn (1974) Myelinated fiber types in the superficial radial nerve of the cat and their central projections. Brain Res. 78: 157-163. 
Brown, A. G., and A. Iggo (1967) A quantitative study of cutaneous receptors and afferent fibers in the cat and rabbit. J. Physiol. (Lond.) 193: 707-733.

Bruce, L. L., J. G. McHaffie, and B. E. Stein (1984) Organization of the hamster trigeminal complex: Projections to superior colliculus, thalamus, and spinal cord. Soc. Neurosci. Abstr. 10: 483.

Burgess, P. R. (1973) Cutaneous mechanoreceptors. In Handbook of Perception, E. E. Carterette and M. P. Friedman, eds., pp. 30-78, Academic, New York.

Burgess, P. R., and E. R. Perl (1973) Cutaneous mechanoreceptors and nociceptors. In Handbook of Sensory Physiology, Vol. 2: Somatosensory System, A. Iggo, ed., pp. 29-78, Springer, New York.

Burgess, P. R., D. Petit, and R. M. Warren (1968) Receptor types in cat hairy skin supplied by myelinated fibers. J. Neurophysiol. 31: 833-848.

Burgess, P. R., J. F. Howe, M. J. Lessler, and D. Whitehorn (1974) Cutaneous receptors supplied by myelinated fibers in the cat. II. Number of mechanoreceptors excited by a local stimulus. J. Neurophysiol. 37: 1373-1386.

Bushnell, M. C., G. H. Duncan, R. Dubner, and L. F. Hu (1984) Activity of trigminothalamic neurons in medullary dorsal horn of awake monkeys trained in a thermal discrimination task. J. Neurophysiol. 52: 170-187.

Casagrande, V. A., J. K. Harting, W. C. Hall, I. T. Diamond, and G. F. Martin (1972) Superior colliculus of the tree shrew: A structural and functional subdivision into superficial and deep layers. Science 177: 444-447.

Cervero, F., A. Iggo, and H. Ogawa (1976) Nociceptor-driven neurons in the lumbar spinal cord of the cat. Pain 2: 5-24.

Chalupa, L. M., and R. W. Rhoades (1977) Responses of visual, somatosensory, and auditory neurons in the golden hamster's superior colliculus. J. Neurophysiol. 270: 595-626.

Chambers, M. R., K. H. Anders, M. von Duering, and A. Iggo (1972) The structure and function of the slowly adapting type II mechanoreceptor in hairy skin. Q. J. Exp. Physiol. 57: 417-445.

Christensen, B. N., and E. R. Perl (1970) Spinal neurons specifically excited by noxious or thermal stimuli: Marginal zone of the dorsal horn. J. Neurophysiol. 33: 293-307.

Clemo, H. R., and B. E. Stein (1982) Somatosensory cortex: A "new" somatotopic representation. Brain Res. 235: 162.

Clemo, H. R., and B. E. Stein (1983) The organization of a fourth somatosensory area of cortex (SIV) in the cat. J. Neurophysiol. 50: 910-925.

Cooper, L. L., and J. O. Dostrovsky (1985) Somatosensory responses of dorsal column nuclei neurons projecting to the dorsal mesencephalon. J. Neurophysiol. 53: 85 .

Craig, A. D., Jr., and D. N. Tapper (1978) The lateral cervical nucleus in the cat: Functional organization and characteristics. J. Neurophysiol. 41: 1511-1534.

Crosby, E. C., and J. W. Henderson (1948) The mammalian midbrain and isthmus regions. II. Fiber connections of the superior colliculus. J. Comp. Neurol. 88: 53-91.

Delgado, J. M. R. (1965) Cerebral structures involved in transmission and elaboration of noxious stimulation. J. Neurophysiol. 18: 261275.

Dräger, U. C., and D. Hubel (1975) Responses to visual stimulation and relationship between visual, auditory, and somatosensory inputs in mouse superior colliculus. J. Neurophysiol. 38: 690-713.

Edwards, S. B., and C. K. Henkel (1978) Superior colliculus connections with the extraocular motor nuclei in the cat. J. Comp. Neurol. 179: 451-468.

Edwards, S. B., C. L. Ginsburgh, C. K. Henkel, and B. E. Stein (1979) Sources of subcortical projections to the superior colliculus in the cat. J. Comp. Neurol. 184: 309-330.

Eisenman, J., S. Landgren, and D. Novin (1963) Functional organization in the main sensory trigeminal nucleus and in the rostral subdivision of the nucleus of spinal trigeminal tract in the cat. Acta Physiol. Scand. Suppl. 59(suppl. 214): 1-44.

Feldman, S. G., and Kruger, L. (1980) An axonal transport study of the ascending projection of medial lemniscal neurons in the rat. $J$. Comp. Neurol. 192: 427-454.

Finlay, B. L., S. E. Schneps, K. G. Wilson, and G. E. Schneider (1978) Topography of visual and somatosensory projections to the superior colliculus of the golden hamster. Brain Res. 142: 224-235.

Fitzgerald, M., and B. Lynn (1977) The sensitization of high threshold mechanoreceptors with myelinated axons by repeated heating. $J$. Physiol. (Lond.) 265: 549-563.

Flink, R., M. Wiberg, and A. Blomqvist (1983) The termination in the mesencephalon of fibres from the lateral cervical nucleus. An anatomical study in the cat. Brain Res. 259: 11-20.

Gaither, N. S., and B. E. Stein (1979) Reptiles and mammals use similar sensory organization in the midbrain. Science 205: 595-597.

Gaze, R. M., and G. Gordon (1954) The representation of cutaneous sense in the thalamus of the cat and monkey. Q. J. Exp. Physiol. 39: 279-304.

Giesler, G. J., Jr., G. Urca, J. T. Cannon, and J. C. Liebeskind (1979) Response properties of neurons of the lateral cervical nucleus in the rat. J. Comp. Neurol. 186: 65-78.

Gordon, B. G. (1973) Receptive fields in deep layers of cat superior colliculus. J. Neurophysiol. 36: 157-178.

Gordon, G., S. Landgren, and W. A. Seed (1961) The functional characteristics of single cells in the caudal part of the spinal nucleus of the trigeminal nerve of the cat. J. Physiol. (Lond.) 158: 544-559.

Graham, J. (1977) An autoradiographic study of the efferent connections of the superior colliculus in the rat. J. Comp. Neurol. 173:629654.

Guilbaud, G., M. Peschanski, M. Gautron, and D. Binder (1980) Neurons responding to noxious stimulation in VR complex and caudal adjacent regions in the thalamus of the rat. Pain $8: 303-318$.

Hand, P. J., and T. van Winkle (1977) The efferent connections of the feline nucleus cuneatus. J. Comp. Neurol. 171: 83-110.

Handwerker, H. O., A. Iggo, H. Ogawa, and R. L. Ramsey (1975) Input characteristics and rostral projection of dorsal horn neurons in the monkey. J. Physiol. (Lond.) 244: 76.

Harrington, T., and M. M. Merzenich (1970) Neural coding in the sense of touch: Human sensations of skin indentations compared with the responses of slowly adapting mechanoreceptive afferents innervating the hairy skin of monkey. Exp. Brain Res. 10: 251-264.

Hayashi, H., R. Sumino, and B. J. Sessle (1984) Functional organization of trigeminal subnucleus interpolaris: Nociceptive and innocuous afferent inputs, projections to thalamus, cerebellum, and spinal cord, and descending modulation from periaqueductal gray. J. Neurophysiol. $51: 890-905$.

Henkel, C. K., and S. B. Edwards (1978) The superior colliculus control of pinna movements in the cat: Possible anatomical connections. $J$. Comp. Neurol. 182: 763-776.

Hoffman, D. S., R. Dubner, R. L. Hayes, and T. P. Medlin (1981) Neuronal activity in medullary dorsal horn neurons of awake monkeys trained in a thermal discrimination task. I. Responses to innocuous and noxious thermal stimuli. J. Neurophysiol. 44: 409-427.

Horch, K. W., R. P. Tuckett, and P. R. Burgess (1977) A key to the classification of cutaneous mechanoreceptors. J. Invest. Dermatol. 69: 75-82.

Hu, J. W., and B. J. Sessle (1979) Trigeminal nociceptive and nonnociceptive neurons: Brain stem intra-nuclear projections and modulation by orofacial, periaqueductal gray and nucleus raphe magnus stimuli. Brain Res. 170: 547-552.

Hubel, D. H. (1960) Single unit activity in lateral geniculate body and optic tract of unrestrained cats. J. Physiol. (Lond.) 150: 91-114.

Huerta, M. F., and J. K. Harting (1984) The mammalian superior colliculus: Studies of its morphology and connections. In Comparative Neurology of the Optic Tectum, H. Vanegas, ed., pp. 687-773, Plenum, New York.

Huerta, M. F., A. Frankfurter, and J. K. Harting (1983) Studies of the principal sensory and spinal trigeminal nuclei of the rat: Projections to the superior colliculus, inferior olive and cerebellum. J. Comp. Neurol. 220: 147.

Iggo, A. (1963) New specific sensory structures in hairy skin. Acta Neuroveg. (Wien) 24: 175-180.

Iggo, A. (1977) Cutaneous and subcutaneous sense organs. Br. Med Bull. 33: 97-102.

Iggo, A., and K. H. Andres (1982) Morphology of cutaneous receptors. Annu. Rev. Neurosci. 5: 1-31.

Ingle, D., and J. M. Sprague (1975) Sensorimotor function of the midbrain tectum. Neurosci. Res. Prog. Bull. 13: 169-287.

Isseroff, R. G., Y. Sarne, A. Carmon, and A. Isseroff (1982) Cortical potentials evoked by innocuous tactile and noxious thermal stimulation in the rat: Differences in localization and latency. Behav. Neurol. Biol. 35: 294-307.

Kawamura, S., and T. Konno (1979) Various types of corticotectal 
neurons of cats as demonstrated by means of retrograde axonal transport of horseradish peroxidase. Exp. Brain Res. 35: 161-175.

Kenshalo, D. R., Jr., and O. Isensee (1983) Responses of primate SI cortical neurons to noxious stimuli. J. Neurophysiol. 50: 1479-1496.

Kenshalo, D. R., Jr., R. B. Leonard, J. M. Chung, and W. D. Willis (1979) Responses of primate spinothalamic neurons to graded and to repeated noxious heat stimuli. J. Neurophysiol. 42: 1370-1389.

Kenshalo, D. R., Jr., G. J. Giesler, Jr., R. B. Leonard, and W. D. Willis (1980) Responses of neurons in primate ventral posterior lateral nucleus to noxious stimuli. J. Neurophysiol. 43: 1594-1614.

Khayyat, G. F., Y. J. Yu, and R. B. King (1975) Response patterns to noxious and non-noxious stimuli in rostral trigeminal relay nuclei. Brain Res. 97: 47-60.

Killackey, H. P., and R. S. Erzurumlu (1981) Trigeminal projections to the colliculus of the rat. J. Comp. Neurol. 201: 221-242.

Kumazawa, T., and E. R. Perl (1978) Excitation of marginal and substantia gelatinosa neurons in the primate spinal cord: Indications of their place in dorsal horn functional organization. J. Comp. Neurol. 177: 417-434.

Lamour, Y., J. C. Willer, and G. Guilbaud (1982) Neuronal responses to noxious stimulation in rat somatosensory cortex. Neurosci. Lett. 29: 35-40.

Lamour, Y., G. Guilbaud, and J. C. Willer (1983) Rat somatosensory (SmI) cortex. I. Characteristics of neuronal responses to noxious stimulation and comparison with responses to non-noxious stimulation. Exp. Brain Res. 49: 39-45.

Larson, M. A., and B. E. Stein (1984) Responses of hamster superior colliculus neurons to graded tactile, thermal, and noxious stimuli. Soc. Neurosci. Abstr. 10: 797.

Larson, M. A., and B. E. Stein (1985) Response characteristics of nociceptive neurons in hamster superior colliculus. Soc. Neurosci. Abstr. 11: 412.

Levick, W. R. (1972) Another tungsten microelectrode. Med. Biol. Eng. 10: 510-515.

Lund, R. D., and K. E. Webster (1967a) Thalamic afferents from the dorsal column nuclei. An experimental anatomical study in the rat. J. Comp. Neurol. 130: 301-312

Lund, R. D., and K. E. Webster (1967b) Thalamic afferents from the spinal cord and trigeminal nuclei. An experimental anatomical study in the rat. J. Comp. Neurol. 130: 313-328.

Mayer, D. J., D. D. Price, and D. P. Becker (1975) Neurophysiological characterization of the anterolateral spinal cord neurons contributing to pain perception in man. Pain $1: 51-58$.

McHaffie, J. G., and B. E. Stein (1982) Eye movements evoked by electrical stimulation in the superior colliculus of rats and hamster. Brain Res. 247: 243-253.

McHaffie, J. G., L. L. Bruce, and B. E. Stein (1984) Trigeminal projections: Comparisons among several mammals. Soc. Neurosci. Abstr. 10: 483.

McHaffie, J. G., K. Ogasawara, and B. E. Stein (1986) Trigeminotectal and other trigeminofugal projections in neonatal kittens: An anatomical demonstration with horseradish peroxidase and tritiated leucine. J. Comp. Neurol. 249: 411-427.

Mehler, W. R. (1969) Some neurological species differences-a posteriori. Ann. NY Acad. Sci. 167: 424-468.

Melzack, R., and K. L. Casey (1968) Sensory, motivational, and central control determinants of pain. In The Skin Senses, D. R. Kenshalo, ed., pp. 423-443, Thomas, Springfield, IL.

Melzack, R., and H. Eisenberg (1968) Skin sensory afterglows. Science 159: 445.

Menetrey, D., G. J. Geisler, Jr., and J. M. Besson (1977) An analysis of response properties of spinal cord dorsal horn neurons to nonnoxious and noxious stimuli in the spinal rat. Exp. Brain Res. 27: $15-33$.

Merzenich, M. M., and T. Harrington (1969) The sense of fluttervibrations evoked by stimulation of the hairy skin of primates: Comparison of human sensory capacity with the response of mechanoreceptive afferents innervating the hairy skin of monkeys. Exp. Brain Res. 9: 236-260.

Mitchell, D., and R. F. Hellon (1977) Neuronal and behavioral responses in rats during noxious stimulation of the tail. Proc. $R$. Soc. London [Biol.] 197: 169-194.

Nagata, T., and L. Kruger (1979) Tactile neurons of the superior colliculus of the cat: Input and physiological properties. Brain Res. 174: 19-37.
Nashold, B. S., Jr., W. P. Wilson, and D. G. Slaughter (1969) Sensations evoked by stimulation in the midbrain of man. J. Neurosurg. 30: 14-24.

Ogasawara, K. (1981) Trigeminotectal projections in cats and the pathway of extraocular muscle proprioception. Neuro-ophthalmol. $1: 219$ 230.

Perl, E. R. (1968) Myelinated afferent fibers innervating the primate skin and their response to noxious stimuli. J. Physiol. (Lond.) 197: 593-615.

Perl, E. R., and D. B. Whitlock (1961) Somatic stimuli exciting spinothalamic projections to thalamic neurons in cat and monkey. Exp. Neurol. 3: 256-296.

Peschanski, M., G. Guilbaud, M. Gautron, and J. M. Besson (1980) Encoding of noxious heat messages in neurons to the ventrobasal thalamic complex of the rat. Brain Res. 197: 401-413.

Price, D. D. (1972) Characteristics of second pain and flexion reflexes indicative of prolonged central summation. Exp. Neurol. 37: 371387.

Price, D. D., and A. C. Browe (1975) Spinal cord coding of graded nonnoxious and noxious temperature increases. Exp. Neurol. 48: 201221.

Price, D. D., and R. Dubner (1977) Neurons that subserve the sensorydiscriminative aspects of pain. Pain 3: 307-338.

Price, D. D., and D. J. Mayer (1975) Neurophysiological characterization of the anterolateral quadrant neurons subserving pain in $M$. mulatta. Pain 1: 59-72.

Price, D. D., R. Dubner, and J. W. Hu (1976) Trigeminothalamic neurons in nucleus caudalis responsive to tactile, thermal, and nociceptive stimulation of monkey's face. J. Neurophysiol. 39: 936953.

Price, D. D., J. W. Hu, R. Dubner, and R. H. Gracely (1977) Peripheral suppression of first pain and central summation of second pain evoked by noxious heat pulses. Pain 3: 57-68.

Price, D. D., R. L. Hayes, M. A. Ruda, and R. Dubner (1978) Spatial and temporal transformations of input to spinothalamic tract neurons and their relation to the somatic sensations. J. Neurophysiol. 41:933947.

Price, D. D., H. Hayashi, R. Dubner, and M. A. Ruda (1979) Functional relationships between neurons of marginal and substantia gelatinosa layers of primate dorsal horn. J. Neurophysiol. 42: 15901608.

Reyes, V., Henny, G. C. Baird, H. G. T. Wycis, and E. A. Spiegel (1951) Localization of centripetal pathways of the human brain by recording evoked potentials. Trans. Am. Neurol. Assoc. 246-248.

Rhoades, R. W. (1981a) Cortical and spinal somatosensory input to the superior colliculus in the golden hamster: An anatomical and electrophysiological study. J. Comp. Neurol. 195: 415-432.

Rhoades, R. W. (1981b) Organization of somatosensory input to the deep collicular laminae in hamster. Behav. Brain Res. 3: 201-222.

Rhoades, R. W., D. R. DellaCroce, and I. Meadows (1981) Reorganization of somatosensory input to superior colliculus in neonatally enucleated hamsters: Anatomical and electrophysiological experiments. J. Neurophysiol. 46: 855-877.

Rhoades, R. W., R. D. Mooney, and M. R. Jacquin (1983) Complex somatosensory receptive fields of cells in the deep laminae of the hamster's superior colliculus. J. Neurosci. 3: 1342-1354.

Robinson, D. A. (1972) Eye movements evoked by collicular stimulation in the alert monkey. Vision Res. 12: 1795-1808.

Schaefer, K. P. (1970) Unit analysis and electrical stimulation in the optic tectum of rabbits and cats. Brain Behav. Evol. 3: 222-240.

Schneider, G. (1969) Two visual systems: Brain mechanisms for localization and discrimination are dissociated by the tectal and cortical lesions. Science 163: 895-902.

Sessle, B. J., and L. F. Greenwood (1976) Inputs to trigeminal brain stem neurones from facial, oral, tooth pulp and pharyngolaryngeal tissues. I. Responses to innocuous and noxious stimuli. Brain Res. 117: 211-226.

Spiegel, E. A., M. Ketzkin, and E. G. Szekely (1954) Pain reactions upon stimulation of the tectum mesencephali. J. Neuropathol. Exp. Ncurol. 13: 212-220.

Sprague, J. M., and T. H. Meikle, Jr. (1965) The role of the superior colliculus in visually guided behavior. Exp. Neurol. 11: 115-146.

Sprague, J. M., W. W. Chambers, and E. Stellar (1961) Attentive, affective, and adaptive behavior in the cat. Science 133: 165-173. 
Steel, R. G. D., and J. H. Torrie (1980) Principles and Procedures of Statistics, 2nd ed., Chap. 17, McGraw-Hill, New York.

Stein, B. E. (1984) Multimodal representation in the SC and optic tectum. In Comparative Neurology of the Optic Tectum, H. Vanegas, ed., pp. 819-841, Plenum, New York.

Stein, B. E., and M. O. Arigbede (1972) Unimodal and multimodal response properties of neurons in the cat's superior colliculus. Exp. Neurol. 183: 179-196.

Stein, B. E., and H. P. Clamann (1981) Control of pinna movements and sensorimotor register in cat superior colliculus. Brain Behav. Evol. 19: 180-192.

Stein, B. E., and J. P. Dixon (1978) Superior colliculus neurons respond to noxious stimuli. Brain Res. 158: 65-73.

Stein, B. E., and J. P. Dixon (1979) Properties of superior colliculus neurons in the golden hamster. J. Comp. Neurol. 183: 269-284.

Stein, B. E., S. J. Goldberg, and H. P. Clamann (1976) The control of eye movements by the superior colliculus in the alert cat. Brain Res. 118: 469-474.

Stein, B. E., B. Magalhães-Castro, and L. Kruger (1976) Relationship between visual and tactile representations in cat superior colliculus. J. Neurophysiol. 39: 401-419.

Stein, B. E., R. F. Spencer, and S. B. Edwards (1983) Corticotectal and corticothalamic efferent projections of SIV somatosensory cortex in cat. J. Neurophysiol. 50: 896-909.

Stewart, W. A., and R. B. King (1963) Fiber projections from the nucleus caudalis of the spinal trigeminal nucleus. J. Comp. Neurol. 121: 271-286.

Tiao, Y.-C., and C. Blakemore (1976) Regional specialization in the golden hamster's retina. J. Comp. Neurol. 39: 401-419.

Torvik, A. (1956) Afferent connections to the sensory trigeminal nuclei, the nucleus of the solitary tract and adjacent structures: An experimental study in the rat. J. Comp. Neurol. 106: 51-132.
Walker, A. E. (1942) The relief of pain by mesencephalic tractotomy. Arch. Neurol. Psychiatry 48: 865-883.

Walker, A. E. (1943) Central representation of pain. Res. Publ. Assoc. Nerv. Ment. Dis. 23: 63-85.

Werner, G., and V. B. Mountcastle (1965) Neural activity in mechanoreceptive cutaneous afferents: Stimulus-response relations, Weber functions and information transmission. J. Neurophysiol. 28: 359-397.

Willis, W. D., D. L. Trevino, J. D. Coulter, and R. A. Maunz (1974) Responses of primate spinothalamic tract neurons to natural stimulation of hindlimb. J. Neurophysiol. 37: 358-372.

Willis, W. D., R. A. Maunz, R. D. Foreman, and J. D. Coulter (1975) Static and dynamic responses of spinothalamic tract neurons to mechanical stimuli. J. Neurophysiol. 38: 587-600.

Wise, S. P., and E. G. Jones (1977) Somatotopic and columnar organization in the corticotectal projection of the rat somatic sensory cortex. Brain Res. 133: 223-235.

Yokota, T. (1983) Oral facial pain. Front. Oral. Biol. 4: 33-54.

Yokota, T., and N. Matsumoto (1983a) Somatotopic distribution of trigeminal nociceptive specific neurons within the caudal somatosensory thalamus of cat. Neurosci. Lett. 39: 125-130.

Yokota, T., and N. Matsumoto (1983b) Location and functional organization of trigeminal wide dynamic range neurons within the nucleus ventralis posteromedialis of the cat. Neurosci. Lett. 39: 231236.

Yokota, T., and N. Nishikawa (1977) Somatotopic organization of trigeminal neurons within caudal medulla oblongata. In Pain in the Trigeminal Region, D. Anderson and B. Matthews, eds., pp. 243257, Elsevier/North-Holland, Amsterdam. 